\title{
Self-Assembly of Alkanethiolates Directs Sulfur Bonding with GaAs(100)
}

\author{
Pablo Mancheno-Posso ${ }^{\mathrm{a}}$, Anthony J. Muscata ${ }^{\mathrm{a}, *}$ \\ ${ }^{a}$ Department of Chemical and Environmental Engineering, University of Arizona, Tucson, \\ Arizona 85721, USA
}

\begin{abstract}
Molecules that contain linear alkane chains self-assemble on a variety of surfaces changing the degree of wetting, lubricity, and reactivity. We report on the reoxidation of $\mathrm{GaAs}(100)$ in air after adsorbing five alkanethiols $\left(\mathrm{C}_{n} \mathrm{H}_{2 n+1}-\mathrm{SH}\right.$ where $n=3,6,12,18,20)$ and one alkanedithiol $\left(\mathrm{HS}-\left(\mathrm{CH}_{2}\right)_{8}-\mathrm{SH}\right)$ deposited from the liquid phase. The alignment of the alkane chains forms a self-assembled layer, however, air diffuses readily through the carbon layer and reaches the surface. The impact of alignment is to improve the bonding of sulfur with the surface atoms which reduces the oxidation rate based on fitting the data to a reaction-diffusion model. The layer thickness and molecular density scale linearly with the number of carbon atoms in the alkane chain. The thickness of the alkanethiolate $\left(\mathrm{RS}^{-}\right)$layer grows by $0.87 \pm 0.06 \AA$ for each $\mathrm{C}$ atom in the chain and the surface density by $0.13 \pm 0.03$ molecule per $\mathrm{nm}^{2}$ per $\mathrm{C}$ atom up to a coverage of 5.0 molecules $/ \mathrm{nm}^{2}$ for $n=20$ or 0.8 monolayer. The surface coverage increases with length because interactions between methylene $\left(\mathrm{CH}_{2}\right)$ groups in neighboring chains reduce the tilt angle of the molecules with the surface normal. The tight packing yields areas per alkanethiolate as low as 20 $\AA^{2}$ for $n=20$. The amount of $\mathrm{C}$ in the layer divided by the chain length is approximately constant up to $n=12$ but increases sharply by a factor of
\end{abstract}

\footnotetext{
* Corresponding author Email address: muscat@email.arizona.edu (Anthony J. Muscat)

$U R L$ : http://muscat. chee.arizona.edu/ (Anthony J. Muscat), +1-520-626-6580 (Anthony J. Muscat)
}

Preprint submitted to Applied Surface Science

September 5, 2016 
$2-4 \times$ for $n=18$ and 20 based on the $\mathrm{C}$ 1s x-ray photoelectron spectroscopy (XPS) peak. Fourier transform infrared (FTIR) spectroscopy shows that the asymmetric methylene stretch shifts continuously to lower wavenumber and the relative peak area increases sharply with the length of the alkane chain. Fitting the data to a reaction-diffusion model shows that for times less than 30 min the surface oxide coverage does not depend on the thickness of the self-assembled layer nor the diffusivity of oxygen through the layer. Instead increasing the layer thickness makes more $\mathrm{S}$ available for bonding with the predominately As termination and reduces the rate coefficient for reaction of oxygen with the GaAs surface.

Keywords: passivation, self-assembled monolayer, liquid phase, alkanethiol, $\operatorname{GaAs}(100)$

2010 MSC: 00-01, 99-00

\section{Acronyms}

$\begin{array}{ll}\text { ALD } & \text { Atomic layer deposition } \\ \text { FTIR } & \text { Fourier-transform infrared spectroscopy } \\ \text { HBT } & \text { Heterostructure bipolar transistor } \\ \text { MOS } & \text { Metal-oxide-semiconductor } \\ \text { MOSFET } & \text { Metal-oxide-semiconductor field-effect transistor } \\ \text { NEXAFS } & \text { Near-edge X-ray absorption fine structure } \\ \text { PL } & \text { Photoluminescence } \\ \text { SAM } & \text { Self-assembled monolayer } \\ \text { SEM } & \text { Scanning electron microscopy } \\ \text { SRV } & \text { Surface recombination velocity } \\ \text { TEMA-Hf } & \text { tetrakis(ethylmethylamino) hafnium } \\ \text { TMA } & \text { Trimethylaluminum } \\ \text { TOF-SIMS } & \text { Time-of-flight secondary ion mass spectrometry } \\ \text { UPW } & \text { Ultrapure water } \\ \text { XPS } & \text { X-ray photoelectron spectroscopy }\end{array}$


Thiol molecules

PT-3C 1-propanethiol, 3 carbon atoms

HT-6C 1-hexanethiol, 6 carbon atoms

ODT-8C 1,8-octanedithiol, 8 carbon atoms, 2 sulfur atoms

DT-12C 1-dodecanethiol, 12 carbon atoms

OT-18C 1-octadecanethiol, 18 carbon atoms

ET-20C 1-eicosanethiol, 20 carbon atoms

Nomenclature

$\begin{array}{ll}\lambda_{i} & i^{t h} \text { eigenvalue } \\ \Phi & \text { Thiele modulus defined by } \sqrt{(k \sigma L) /(D A)} \\ \sigma & \text { Surface site density of } \mathrm{GaAs}(100)\left(\mathrm{sites} / \mathrm{cm}^{2}\right) \\ \theta & \text { Fraction of surface sites that have oxidized } \\ A & \text { Avogadro's number } \\ A_{i} & \text { Coefficients that depend on the eigenvalues } \lambda_{i} \\ C(t, z) & \text { Concentration of oxygen in the alkanethiolate layer }\left(\mathrm{mol} / \mathrm{cm}^{3}\right) \\ C_{\mathrm{O}_{2}}^{\text {air }} & \text { Concentration of oxygen in air } \\ D & \text { Diffusivity of oxygen in the alkanethiolate layer }(\mathrm{cm} / \mathrm{s}) \\ k & \text { Second-order rate coefficient for reaction of oxygen with } \mathrm{GaAs} \\ L & \text { surface (cm }{ }^{3} / \text { mol s) } \\ t & \text { Thickness of the alkanethiolate layer }(\mathrm{cm}) \\ z & \text { Time (s) } \\ & \text { Position in the alkanethiolate layer perpendicular to the surface } \\ & \text { where } 0 \text { is defined at the top of the thiolate film at the interface } \\ & \text { with air (cm) }\end{array}$

\section{Introduction}

5 The continuous scaling and performance improvement of metal-oxide-semiconductor field-effect transistors (MOSFETs) in Si-based technology is limited by power dissipation [1. Reducing the operating voltage can decrease energy losses, but 
not without affecting the switching speed of the device. Strained Si is currently used to increase the charge mobility of high performance MOSFET devices, but this effect will saturate with future scaling 2. Higher mobility substrate materials are consequently needed to continue scaling MOSFETs without increasing energy losses and reducing device performance. Several problems must be solved before high mobility materials such as III-Vs can be used in manufacturing. III-V surfaces lack a high quality insulating native oxide like Si. Instead, the oxides of III-V substrates create interface defects and contain border traps that degrade device performance [3]. Removal of the oxides of both the III and $\mathrm{V}$ atom is readily accomplished using liquid phase chemistries [4, 5, 6, 7, 8, 9, but exposure to air reoxidizes the surface. A major challenge for III-V device technology is the development of surface protection schemes during ambient exposure that can be easily removed in vacuum when no longer needed.

Several methods have been used to prevent surface reoxidation and defect formation. Inorganic precursors containing sulfur atoms have been widely used to passivate dangling bonds of III-V compound semiconductor surfaces. Liquid phase passivation is commonly carried out by immersion in aqueous or organic solutions of $\mathrm{Na}_{2} \mathrm{~S} \cdot 9 \mathrm{H}_{2} \mathrm{O}$ [10, 11, 12, 13, $\left(\mathrm{NH}_{4}\right)_{2} \mathrm{~S}$ [14, 15, 16, 17, 18, 19, or $\left(\mathrm{NH}_{4}\right)_{2} \mathrm{~S}_{x}$ 20, 21, 22, 23, 24, 25, 26, while gas phase deposition can be done through the thermal or electrochemical decomposition of $\mathrm{Ag}_{2} \mathrm{~S}$ [27, 28] or upon exposure to $\mathrm{H}_{2} \mathrm{~S}$ vapor [29, 30, 31, 32. Sulfur deposition from aqueous $\mathrm{Na}_{2} \mathrm{~S} \cdot 9 \mathrm{H}_{2} \mathrm{O}$ reduced the surface recombination velocity (SRV) on GaAs to 1000 ${ }_{30} \mathrm{~cm} / \mathrm{s}$, which is lower than untreated GaAs $\left(10^{6} \mathrm{~cm} / \mathrm{s}\right)$ and comparable to the ideal AlGaAs/GaAs interface [11, 10]. Liquid phase treatments with $\left(\mathrm{NH}_{4}\right)_{2} \mathrm{~S}$ and $\left(\mathrm{NH}_{4}\right)_{2} \mathrm{~S}_{x}$ decreased the SRV on sulfur-coated GaAs [33, 34, 22] and reduced As and Ga oxides on GaAs and InGaAs [14, 20, 17, 19. Treating GaAs with $\mathrm{Na}_{2} \mathrm{~S} \cdot 9 \mathrm{H}_{2} \mathrm{O}$ showed a greater increase in photoluminescence (PL) inten35 sity than processes using $\left(\mathrm{NH}_{4}\right)_{2} \mathrm{~S}[35$ ] and alcohol solutions of both compounds improved this intensity when compared to aqueous solutions [34. Both the reduction in SRV and the increase in PL intensity are correlated to the decrease of defective surface states. In additional studies, Tiedje et al. passivated GaAs 
using $\mathrm{H}_{2} \mathrm{~S}$ vapor at room temperature and compared the performance with a

$40 \mathrm{Na}_{2} \mathrm{~S} \cdot 9 \mathrm{H}_{2} \mathrm{O}$ treatment [29, 36]. Ultraviolet photoemission spectroscopy showed that $\mathrm{Na}_{2} \mathrm{~S} \cdot 9 \mathrm{H}_{2} \mathrm{O}$ did not completely remove surface oxides and produced an incomplete $\mathrm{S}$ layer [36]. On the other hand, deposition of $\mathrm{S}$ atoms from $\mathrm{H}_{2} \mathrm{~S}$ requires thermal activation of the precursor, and subsequent annealing leads to the formation of $\mathrm{GaS}_{x}$ species that are stable in air or water for short exposures

45 29, 31. The electrical properties of AlGaAs/GaAs heterostructure bipolar transistors (HBTs) and GaAs homojunctions after passivation with liquid solutions of $\mathrm{Na}_{2} \mathrm{~S} \cdot 9 \mathrm{H}_{2} \mathrm{O}$ and $\left(\mathrm{NH}_{4}\right)_{2} \mathrm{~S}$ were also reported [10, 37, 38]. The current gain of AlGaAs/GaAs structures was enhanced by a factor of 60 at low collector currents and was directly correlated to a reduction in SRV [10]. This enhancement, according to the authors, was stable for several days. An improvement in the current gain was also observed for InGaAs/InP HBTs [17.

The effectiveness of S passivation towards ambient oxidation can be directly measured using X-ray photoelectron spectroscopy (XPS). Kim et al. studied the passivation of GaAs using $\left(\mathrm{NH}_{4}\right)_{2} \mathrm{~S}_{x}$ in the vapor and aqueous phase [39]. GaAs etched with $\mathrm{HCl}$ was exposed to $\left(\mathrm{NH}_{4}\right)_{2} \mathrm{~S}_{x}$ vapor for 3 min or dipped in $\left(\mathrm{NH}_{4}\right)_{2} \mathrm{~S}_{x}$ for $10 \mathrm{~min}$. Scanning electron microscopy (SEM) and XPS after vapor phase treatment showed the formation of polysulfide agglomerates. The bulk-sensitive Ga 3d and As 3d XPS peaks of vapor-treated GaAs showed that oxides were not completely removed and that this surface oxidized continuously during the first $30 \mathrm{~min}$ of air exposure. The liquid phase treatment also showed incomplete oxide removal, but exhibited a reduced oxidation rate during the same period of time, after which both liquid and vapor treatments were unable to prevent oxidation and displayed a similar oxide re-growth over 10 hours of exposure. Although the vapor treatment formed agglomerates with a higher S content than the liquid treatment, this $\mathrm{S}$ quickly evaporated during the first 30 min. The Ga and As $3 \mathrm{~d}$ peaks were also used by Petrovykh et al. to assess substrate oxidation of InAs treated with $\left(\mathrm{NH}_{4}\right)_{2} \mathrm{~S}_{x}$ solutions [25. This passivation prevented the oxidation of As atoms for over $20 \mathrm{~min}$ of air exposure and after about 5 days the As oxide levels were 3 times lower than samples 
etched with $\mathrm{HCl}$. The In atoms, however, were oxidized at a higher rate. This selective oxidation was a result of the surface structure, which was comprised of an outermost layer of In-S on top of an As rich layer.

Atomic layer deposition (ALD) of a thin dielectric leaves a permanent passivation layer on a semiconductor surface [40, 41, 42, 43]. Alumina $\left(\mathrm{Al}_{2} \mathrm{O}_{3}\right)$

75 ALD using trimethylaluminum (TMA) and water is the most common process because the substrate oxide is sacrificial and $\mathrm{Al}$ replaces the substrate atoms bound to $\mathrm{O}$ [40, 41, 44, 45]. However, the reaction depends on the metal precursor and the oxidation state of the substrate atom. For instance, removal of GaAs oxides was readily accomplished using TMA, but not $\mathrm{HfCl}_{4}$ 40. TMA removed $\mathrm{As}^{+3}$ and tetrakis(ethylmethylamino) hafnium (TEMA-Hf) removed $\mathrm{As}^{+5}$ [44. A recent study by McDonnell et al. showed that reoxidation of GaAs occurs after ambient exposure of samples even with thin films ( 1 nm) of $\mathrm{Al}_{2} \mathrm{O}_{3}$ and $\mathrm{HfO}_{2}$ deposited via $\mathrm{ALD}$ [46]. In comparison with typical $\mathrm{NH}_{4} \mathrm{OH}$ treatments, $\mathrm{S}$ deposition using $\left(\mathrm{NH}_{4}\right)_{2} \mathrm{~S}$ before $\mathrm{Al}_{2} \mathrm{O}_{3}$ ALD with TMA and wa${ }_{85}$ ter decreased the frequency dispersion in MOS capacitors and band bending at the interface between $\mathrm{Al}_{2} \mathrm{O}_{3}$ and GaAs [47, 43].

Another method to control surface reoxidation is the deposition of alkanethiols to form a diffusion barrier for oxygen, as well as to passivate dangling bonds through thiolate bonding. Since the reports of Lunt et al. [48] and Sheen et al. 90 [49 on the deposition of organic thiols and the formation of a self-assembled monolayer (SAM) of 1-octadecanethiol on $\operatorname{GaAs}(100)$, respectively, a wide variety of alkanethiol SAMs have been used to make GaAs suitable for biochemical and electronic applications [50, 51, 52, 53, 54, 55, 56, 57, 58, 59, 60, 61. Alkanethiols have been adsorbed by immersion in the pure thiol compound [49, 50], ${ }_{95}$ from alcohol solutions $[62,51,63,53$, or from the vapor phase [64, 65, 56, 60]. Several studies on the characterization of the oxide re-growth upon ambient exposure after liquid phase passivation [50, 53, 66, 55, and on the role of the carbon chain length in oxidation protection 66, 67, 68, 58, have been reported. SAMs of methyl-terminated alkanethiols deposited from alcohol solutions and with more than $16 \mathrm{CH}_{2}$ groups formed more organized monolayers due to in- 
creased van der Waals interactions, thus increasing thiol coverage and protecting the GaAs substrate from ambient oxidation [67, 58. Liquid phase treatments with alkanethiols, in particular, are relatively simple compared to methods that require vacuum enabling the development of electrical and optical biosensors [25, 69].

The stability of GaAs treated with molten 1-octadecanethiol and stored under a nitrogen ambient was studied using Raman spectroscopy [50, since changes in the intensity of the longitudinal optic and phonon-plasmon modes are related to changes in the width of the surface depletion region. Based on the increase of this width, a sample treated with the thiol and exposed to ambient conditions showed only a slight reoxidation after one week of exposure, while samples stored under nitrogen were stable for a period of 4 months. In another study, a stability of at least 2 weeks against ambient oxidation was reported for thiol-treated $\mathrm{GaAs}(001)$ [53. GaAs oxides were etched with $\mathrm{NH}_{4} \mathrm{OH}$ and subsequently treated with 1-octadecanethiol in an alkaline solution in ethanol for 20 hours and under a nitrogen environment. Near-edge X-ray absorption fine structure (NEXAFS) spectroscopy showed that the thiol layer had a tilt angle of $14^{\circ}$, corresponding to a layer thickness of $23.8 \AA$. The water contact angle was $111^{\circ}$. The bulk-sensitive Ga and As 3d XPS peaks showed that after thiol deposition oxygen was reduced below detection limits, but peaks due to As-S and Ga-S species were not resolved. After an exposure of 2 weeks the substrate oxides species grew to about one quarter that on a native oxide sample. SAMs of 1-dodecanethiol were deposited from a solution in methanol under a nitrogen atmosphere and immersion over night [66. Based on transmission ${ }_{25}$ Fourier-transform infrared spectroscopy (FTIR) and XPS analysis, these SAMs exhibited a disordered structure and incomplete oxide removal compared to molecules with longer chains containing 14, 16 and $18 \mathrm{C}$ atoms. The water contact angle varied from $110^{\circ}$ for 1-dodecanethiol to $112^{\circ}$ for 1-octadecanethiol. After 3 days of exposure, the thickness of the oxide layer of a sample treated with 1-dodecanethiol was more than 4 times thicker than the initial oxide thickness. In addition, recent studies on the deposition of short- and long-chain 
thiols showed that the former had poor order and coverage, while the latter formed more dense and ordered monolayers [54, 57, 58. Ellipsometry showed that layers formed by thiols with $14 \mathrm{C}$ atoms or less were thinner than the length of the molecule, because the molecules were loosely packed and disordered [54] and high-resolution XPS and FTIR spectroscopy showed that layers of 1-octadecanethiol were more dense and ordered than layers of 1-dodecanethiol [57, 58. A study on the self-assembly of alkanethiols on Pt oxide and metallic Pt showed that the order and surface packing of the layers improves on the oxide-free surface and with long $\mathrm{C}$ chains $[70$. A layer formed by a thiol with 20 $\mathrm{C}$ atoms, 1-eicosanethiol, was about $31 \AA$ thick and had a water contact angle of $113^{\circ}$ on a metallic Pt surface, while a thickness of $7 \AA$ was achieved on an oxide surface due to increased disorder. A well-ordered layer of this thiol on a Pd substrate was also formed by immersion in an ethanol solution or by microcontact printing with a PDMS stamp, as shown by the ellipsometry thickness of $28 \AA$ obtained in both cases and an average contact angle of $115^{\circ}$ [71. Time-of-flight secondary ion mass spectrometry (TOF-SIMS) showed that UV photooxidation of alkanethiol SAMs on GaAs(001) depends on the length of the C chain 72]. The increased order of long alkanethiols with 16, 18, and $20 \mathrm{C}$ atoms yielded different reaction kinetics compared to chains with 11 and $14 \mathrm{C}$ atoms. The deposition of a layer of partially fluorinated alkanethiols was studied by $\mathrm{Lu}$ et al. 73. SAMs of molecules containing the same number of $\mathrm{CH}_{2}$ groups but a different number of $\mathrm{C}-\mathrm{F}$ bonds showed different protection against oxidation depending on the length of the SAM. The molecules with longer fluorocarbon segments, which formed thicker films, exhibited greater protection against ambient oxidation as shown by the As and Ga 3d XPS regions. NEXAFS spectra showed that the methylene and fluorocarbon segments of the molecule had different orientations with respect to the surface, and the order of the fluorocarbon segments decreased with the length of these segments. The packing density and order of the SAM, and the effective protection of the substrate, was dominated by the fluorocarbon segments.

XPS and ellipsometry showed that the adsorption of 1,8-octanedithiol, de- 
spite being a relatively short molecule, yielded an organized and dense monolayer, based on the presence of two peaks in the $S 2 p$ region due to thiolate and free thiol groups, and an ellipsometry thickness of $14 \AA$, which agrees with the length of the molecule [54]. A comparison of monothiols and dithiols was performed by Aqua et al. [55] XPS showed that a 1-nonanethiol layer was 11.7 $\AA$ thick and a 1,9-nonanedithiol layer was $14.3 \AA$ thick. The authors found that after 10 days of ambient exposure the thickness of a 1,9-nonanedithiol monolayer did not change, while that for 1-nonanethiol decreased to half of the initial thickness. Although the dithiol formed a more stable monolayer, the substrate was oxidized after 3 days and shorter exposure times were not presented. As shown by PL intensity, similar levels of interface states were achieved by thiols with less than $6 \mathrm{C}$ atoms or benzene rings and by aqueous sulfide treatments 175 [48. Despite these results, the use of varied cleaning treatments, indirect methods of characterization of oxide re-growth, such as PL or Raman spectroscopy, and XPS states with different surface sensitivities, prevents quantitative comparison of the protection of thiol layers towards exposure to ambient over short and relatively long periods of time.

In this study, we investigated the adsorption of a series of five alkanethiols and one alkanedithiol on $\mathrm{GaAs}(100)$ to understand how these molecules protect the surface from reoxidation when exposed to air. Protection could be due either to the resistance of a hydrophobic carbon film to oxygen diffusion or to the resistance of a S-terminated surface to react with oxygen. The oxides on GaAs were removed using a liquid phase process sequence and alkanethiolates with $\mathrm{C}$ chain lengths from 3 to 20 atoms were adsorbed from the liquid phase. The surface was monitored as a function of time in air using ellipsometry and the surface sensitive Ga and As 2p XPS states. The oxide coverage data from these two techniques were fit with a reaction-diffusion model. For short times defined as $30 \mathrm{~min}$ or less the model shows that oxygen diffusion through the layers is fast. The surface resists oxidation because the kinetics are slowed for the reaction of oxygen and water vapor when sulfur atoms terminate the GaAs surface. 


\section{Experimental}

195

2.1. Materials

Semiconductor grade acetone, hydrofluoric acid (HF, 49\%), hydrochloric acid $(\mathrm{HCl}, 37 \%)$ and hydrogen peroxide $\left(\mathrm{H}_{2} \mathrm{O}_{2}, 30 \%\right)$ were obtained from Honeywell. Ethanol (anhydrous, 99.5\%), 1-propanethiol (PT-3C, 99\%), 1-hexanethiol (HT6C, 95\%), 1,8-octanedithiol (ODT-8C, 97\%), 1-dodecanethiol (DT-12C, 98\%), and 1-octadecanethiol (OT-18C, 98\%) were purchased from Sigma-Aldrich, and 1-eicosanethiol (ET-20C, 98\%) from Alfa-Aesar. The thiol acronyms include the number of $\mathrm{C}$ atoms in the alkane chain. All the solvents and reagents were used as received.

\subsection{Thiol Deposition}

Undoped $\operatorname{GaAs}(100)$ wafers $\left(>1 \times 10^{8} \Omega\right.$-cm, $\left.625 \mu \mathrm{m}\right)$ were obtained from Freiberger Compound Materials. Samples were cleaved into $1 \times 1.5 \mathrm{~cm}^{2}$ coupons and cleaned by sonication in acetone and ultrapure water (UPW, $18 \mathrm{M} \Omega-\mathrm{cm}$ ) for 1 min each. Following a rinse with UPW and $\mathrm{N}_{2}$ dry, samples were immersed consecutively for $1 \mathrm{~min}$ in $0.28 \mathrm{M} \mathrm{HF}$ and for $2 \mathrm{~min}$ in $1.0 \mathrm{M} \mathrm{H}_{2} \mathrm{O}_{2}$. This sequence was repeated twice with UPW rinses and $\mathrm{N}_{2}$ drying between each step. Samples were finished with an immersion in the same dilute HF solution for 1 min and, without rinsing or drying, in $1.0 \mathrm{M} \mathrm{HCl}$ for $1 \mathrm{~min}$. The removal of GaAs oxides using $\mathrm{HCl}$ solutions produces a highly reactive surface enriched with elemental As [4, 5, 174, 6], which readily oxidizes when exposed to the ambient. After the $\mathrm{HCl}$ treatment, the As to Ga molar ratio was 1.8, and the surface was terminated with $\mathrm{Cl}$ atoms based on XPS data. The $\mathrm{Cl}$ layer could be removed by immersion in pure ethanol. The corresponding XPS spectra of the $\mathrm{Cl} 2 \mathrm{p}$ region for $\mathrm{HCl}-$ treated GaAs without an UPW rinse and subsequent treatments are provided in the Supporting Information. To minimize air exposure after etching with $\mathrm{HCl}$, samples were promptly transferred without drying to a continuously stirred 4 $\mathrm{mM}$ solution of the alkanethiol in ethanol, where the deposition was carried out for $20 \mathrm{~min}$. In this transfer, a wet film containing $\mathrm{HCl}(<0.1 \mathrm{~mL})$ was carried on 
the sample surface into the thiol solution yielding an $\mathrm{HCl}$ concentration of less than $2 \mathrm{mM}$. Following deposition, samples were swished in fresh ethanol, dried with $\mathrm{N}_{2}$, and loaded in an ultra high vacuum system within 3 min during which the sample was exposed to the ambient air, unless otherwise stated. The surface preparation and deposition steps were all carried out at room temperature.

\subsection{Characterization}

Overlayer thickness after thiol deposition was measured with a spectroscopic ellipsometer (J.A. Woollam, M-2000) at an incident angle of $75^{\circ}$. A simple model consisting of a GaAs oxide layer on a GaAs substrate (GaAs/GaAs oxide) was used, owing to the close match of the refractive indexes of the oxide (1.8) and the thiol molecules (1.5) 75 and the indeterminate structure of the interface. To monitor oxide re-growth under ambient conditions, samples were left on the ellipsometer stage and measurements were taken every 10 min for the first two hours, and every 30 min thereafter.

XPS was performed with a Physical Electronics (Model 549) instrument equipped with a non-monochromatic dual-anode $\mathrm{Al} / \mathrm{Mg} \mathrm{X}$-ray source and a double-pass cylindrical mirror analyzer. The $\mathrm{Al} \mathrm{K} \alpha$ X-ray source $(1486.6 \mathrm{eV})$ was used for all the analyses. The analysis chamber was maintained at $10^{-9}$ Torr. The $\mathrm{Au} 4 \mathrm{f}_{7 / 2}$ peak at $84.0 \mathrm{eV}$ had a full-width half-maximum of 1.9 $\mathrm{eV}$ and was used for calibration. A pass energy of $50 \mathrm{eV}$ was used for highresolution scans with incremental steps of $0.1 \mathrm{eV}$. The duration of the XPS measurements was approximately $2 \mathrm{~h}$. The As $3 \mathrm{~d}$ state at $41.1 \mathrm{eV}$ served as the reference to correct for sample charging [76]. Shirley background subtraction [77] and fitting of Voigt lineshapes was done using the analysis packages in Igor Pro (WaveMetrics, Inc., v.6.2). Atomic concentrations and ratios were calculated assuming homogeneous layers and using sensitivity factors from the literature 78. Layer thickness and surface coverage were calculated from XPS data using quantitative analysis procedures $[79,80,81,82,83$. All of the surface characterization was carried out at room temperature.

Water contact angle measurements were done using a Ramé-Hart Standard 
Goniometer (Model 250). Sessile UPW droplets with a volume of $5 \mu \mathrm{L}$ were used and an average of 3 measurements on each sample is reported. A single beam spectrometer (Nicolet Nexus 670) equipped with a MCT detector was used for transmission FTIR. Spectra were collected at $4 \mathrm{~cm}^{-1}$ resolution and 200 scans were co-added. Contact angle measurements and FTIR analysis were carried out within $10 \mathrm{~min}$ of film deposition. Surface topography was imaged $e x$ situ using atomic force microscopy (AFM, Digital Instruments Multimode IIIa). Imaging was done using tapping mode over $500 \times 500 \mathrm{~nm}^{2}$ areas. All of the error bars reported in the paper correspond to a $95 \%$ margin of error. Confidence intervals in linear fitting results correspond to one standard deviation.

\section{Results}

\subsection{SAM Formation}

265

Figure 1(a) shows the increase in the overlayer thickness when thiol-treated GaAs was exposed to air. Contributions from both surface oxides and the alkanethiol film are possible. At the shortest air exposure time of $3 \mathrm{~min}$, the thickness varied from $9.8 \pm 0.2 \AA$ for PT-3C (1-propanethiol, $3 \mathrm{C}$ atoms) to $25.5 \pm 0.5 \AA$ for ET-20C (1-eicosanethiol, $20 \mathrm{C}$ atoms). A thickness of 13.7 $270 \pm 0.4 \AA$ was measured for ODT-8C (1,8-octanedithiol), which was studied for comparison due to the increased stability and order of dithiol monolayers reported in the literature [54, 55]. Table 4 and line markers on the left axis in Figure 1(a) show the calculated thickness of each alkanethiol, assuming the $\mathrm{C}$ chains are fully extended and oriented normal to the substrate surface. The initial values measured for the short-chain thiols (PT-3C, HT-6C, and ODT-8C) were greater than the maximum length of each molecule, whereas that for the long-chain thiols (DT-12C, OT-18C and ET-20C) was less than the maximum. The higher initial thickness for the short-chain molecules is due to formation of oxides during sample transfer to the ellipsometer. The lower initial thickness for the surfaces covered by the long-chain molecules indicates that little or no oxide formed. The difference of about $3 \AA$ for OT-18C and $1.4 \AA$ for ET-20C 
is due to tilting of the molecules in these layers with respect to the surface normal. Based on ellipsometry and calculated molecular lengths, the tilting angle from the surface normal decreased with increasing $\mathrm{C}$ chain length from $28^{\circ}$ for OT-18C to $19^{\circ}$ for ET-20C. The tilting angle is obtained from the angle formed by the theoretical length of the molecule, assuming the molecule is normal to the surface, and the length of the molecule obtained from ellipsometry.

The thickness of all of the overlayers increased with time as the substrate oxidized. The oxide re-growth for each thiol was relatively fast during the first hour of exposure, then slowed and reached a plateau from 150 to $240 \mathrm{~min}$ independent of the length of the $\mathrm{C}$ chain. Over an exposure of four hours, the increase in the overlayer thickness was almost $3 \AA$ for PT-3C, in contrast to changes of $5.3 \AA$ for HT-6C, $4.5 \AA$ for ODT-8C, $4.3 \AA$ for DT-12C, $4.1 \AA$ for OT-18C, and $2.4 \AA$ for ET-20C. The chain with $3 \mathrm{C}$ atoms showed the smallest change because the substrate was oxidized before the first measurement. The reduction in the change over $4 \mathrm{~h}$ from HT-6C to ET-20C shows that the resistance to oxidation increased with the length of the $\mathrm{C}$ chain. The growth rates obtained from linear fits of the data for the first $30 \mathrm{~min}$ of exposure were 0.043 , 0.066, $0.076,0.042$ and $0.026 \AA / \mathrm{min}$ for PT-3C, ODT-8C, DT-12C, OT-18C, and ET-20C, respectively. The re-growth curve for ODT-8C, despite having an extra thiol group, was in accord with the length of the molecule, and did not deviate significantly from the trend in the monothiols. All the thiols, except for ET-20C, exhibited oxidation after 10, 20, and 30 min of ambient exposure. The ET-treated surface showed no variation in thickness during $30 \mathrm{~min}$ of exposure within the measurement error.

The initial (3 min of ambient exposure) and final (240 min) overlayer thickness as a function of the number of $\mathrm{C}$ atoms are plotted in Figure 1(b). The thickness reported was obtained from ellipsometry and is not corrected for the tilt angles of the molecules with respect to the surface normal. A linear fit of the initial thickness yields a slope of $0.87 \pm 0.06 \AA / \mathrm{CH}_{2}$ and an intercept equal to $6.8 \pm 0.7 \AA$ A. After $240 \mathrm{~min}$ of exposure, linear regression yielded a slope of 0.82 $\pm 0.06 \AA / \mathrm{CH}_{2}$ and an intercept equal to $11.4 \pm 0.8 \AA$. The calculated length 
of the molecule assuming a vertical orientation produced a slope of $1.22 \pm 0.04$ $\AA / \mathrm{CH}_{2}$ and an intercept equal to $2.6 \pm 0.6 \AA$, in agreement with the literature 84.

In Figure 2 the symmetric $\mathrm{CH}_{2}$ stretch $\left(\nu_{s}-\mathrm{CH}_{2}\right)$ of an ET-20C (OT-18C) layer appeared at $2850(2849) \mathrm{cm}^{-1}$ and the asymmetric stretch $\left(\nu_{a}-\mathrm{CH}_{2}\right)$ at $2918(2919) \mathrm{cm}^{-1}$. For ET-20C (OT-18C), a peak due to the asymmetric stretch of $\mathrm{CH}_{3}$ groups $\left(\nu_{a}-\mathrm{CH}_{3}\right)$ was observed at $2960(2961) \mathrm{cm}^{-1}$. As reported in the 320 literature for thiol monolayers on gold substrates [84, the position and intensity of these peaks provide information on the order, orientation, and coverage [84, 49. Specifically, the location of the $\nu_{a}-\mathrm{CH}_{2}$ vibrational mode is indicative of the order of the molecules, while the intensity provides information on the coverage. Since the asymmetric stretching peak of bulk crystalline OT-18C is at $2919 \mathrm{~cm}^{-1}$ [58, the degree of order in the monolayer is assessed by the proximity to this peak. Thus, in the case of ET-20C and OT-18C, the observed peak positions correspond to a layer composed of closely-packed chains with a crystalline-like structure [66, 53, 58. The peaks for the symmetric and asymmetric $\mathrm{CH}_{2}$ stretches of DT-12C at 2851 and $2923 \mathrm{~cm}^{-1}$ (Figure 2 were significantly less intense and shifted to higher wavenumber because of reduced order and density of this layer. The FTIR results for the DT-12C layer indicate that the difference between the ellipsometric thickness of $16.8 \AA$ and the molecular length of $17 \AA$ is due to disorder of the molecules in the layer and a greater oxide contribution than the thiols with longer $\mathrm{C}$ chains. The relative peak areas of the $\nu_{a}-\mathrm{CH}_{2}$ stretch for OT-18C and ET-20C increased by factors of 7 and 20 with respect to the peak area of the DT-12C layer.

\subsection{Brief (3 min) Air Exposure}

Figure 3(a) shows the XPS spectra of the As $2 p$ and Ga $2 p$ states after deposition of the series of six alkanethiols and $3 \mathrm{~min}$ of ambient exposure. All the peaks were attenuated due to thiol adsorption and this attenuation increased with the C chain length. The As and Ga 2p XPS spectra for OT-18C and ET20C are multiplied by factors of 2 and 3, respectively, to aid comparison. In 


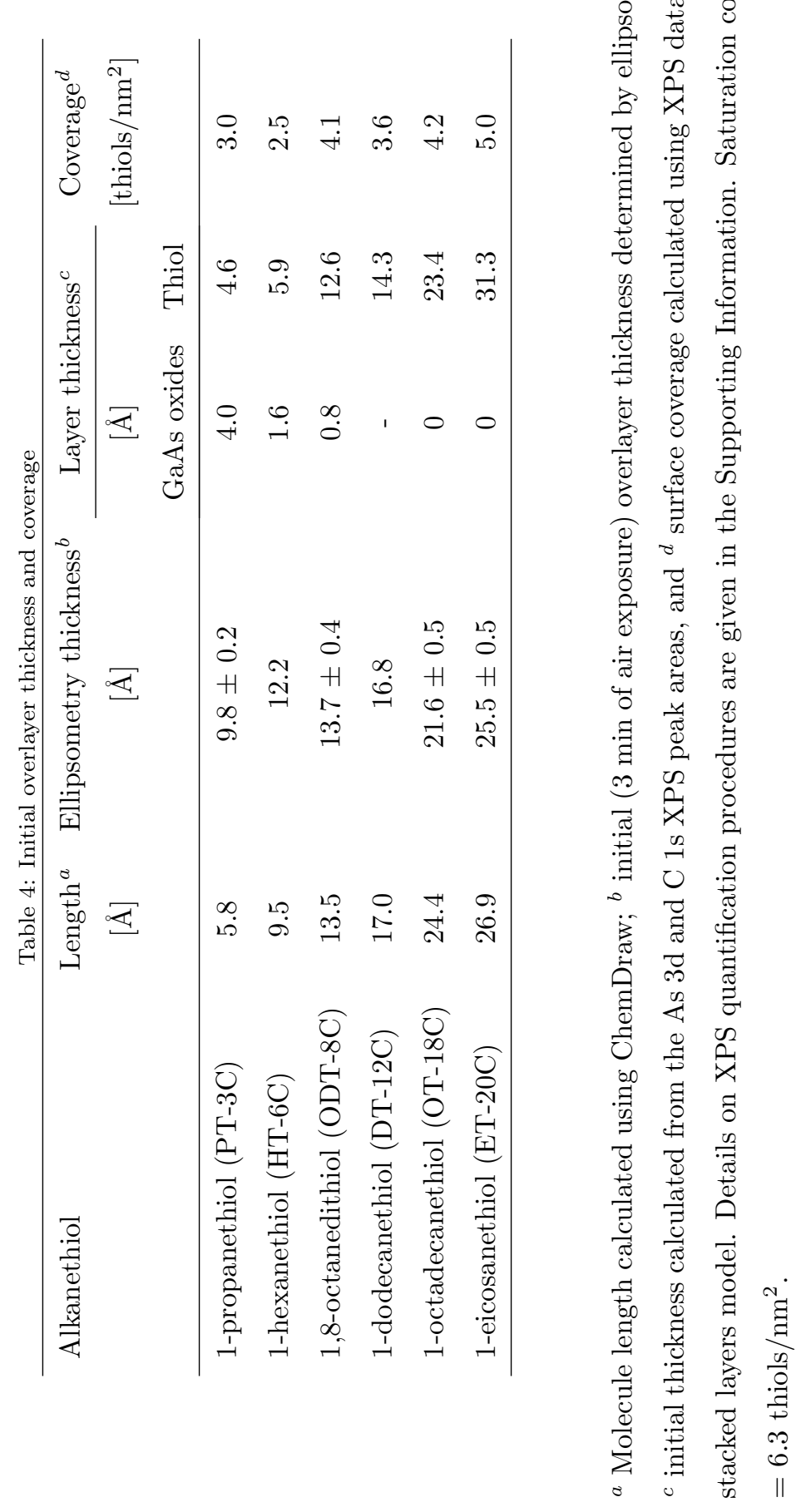


the As $2 p$ XPS region, the peak at a binding energy shift $(\triangle \mathrm{BE})$ of $+3.2 \mathrm{eV}$ from the bulk As peak $(1323.0 \mathrm{eV})$ is due to the $\mathrm{As}^{+3}$ oxide state $\left(\mathrm{As}_{2} \mathrm{O}_{3}\right)$ [85, 46. The intensity of the $\mathrm{As}^{+3}$ oxide state progressively decreased from PT$3 \mathrm{C}$ to DT-12C and was reduced below detection limits for OT-18C and ET-20C, indicating a gradual reduction of oxides for the thiols with longer $\mathrm{C}$ chains. A third peak located between the bulk and the $\mathrm{As}^{+3}$ oxide state corresponds to a combination of $\mathrm{As}^{2+}(\Delta \mathrm{BE}=+2.6 \mathrm{eV})$ and $\mathrm{As}^{+1}(\Delta \mathrm{BE}=+1.3 \mathrm{eV})$ oxide states, elemental $\mathrm{As}(\Delta \mathrm{BE}=+0.5 \mathrm{eV})$ and $\mathrm{As}-\mathrm{S}$ bonding of the thiol $(\Delta \mathrm{BE}=$ $+1.3 \mathrm{eV})[85$, 46, 57, 86]. This peak shifted to lower binding energies and was attenuated from PT-3C to ET-20C due to smaller contributions from suboxide states and an increase in As-S bonding. For OT-18C and ET-20C layers, the peak at $\Delta \mathrm{BE}=+1.3 \mathrm{eV}$ is due only to As-S bonds, since the $\mathrm{As}^{+3}$ oxide and suboxide states were not detected. The ratio of the peak due to As-S bonds to the bulk As peak is 0.07 and 0.13 for OT-18C and ET-20C, respectively. The slight shift (within a $0.3 \mathrm{eV}$ range) in the position of the bulk As $2 \mathrm{p}$ peaks to lower binding energy from PT-3C to ET-20C is attributed to band bending and charge donation from the $\mathrm{C}$ chain.

In the $\mathrm{Ga} 2 \mathrm{p}$ region, the peak located at $1117.1 \mathrm{eV}$ corresponds to Ga-As bonds from the bulk substrate [19. A second peak at higher binding energy is attributed to the contribution of the $\mathrm{Ga}^{+3}(\Delta \mathrm{BE}=+1.1 \mathrm{eV})$ and $\mathrm{Ga}^{+1}(\Delta \mathrm{BE}$ $=+0.6 \mathrm{eV})$ oxide states, and Ga-S bonding of the thiol $(\Delta \mathrm{BE}=+0.4 \mathrm{eV})$ 19, 86, 46. Similarly, the peak at high binding energy decreased from PT-3C to ODT-8C, because of a lower oxide re-growth that decreased the contribution to the $\mathrm{Ga}^{+3}$ and $\mathrm{Ga}^{+1}$ states for longer $\mathrm{C}$ chains. For DT-12C, this peak corresponds to the contribution of Ga oxides and Ga-S bonds. In the case of OT-18C and ET-20C, oxide states were not detected and the Ga-S state was not resolved due to the close proximity to the bulk Ga-As peak and the termination 370 of the substrate by As. The ratio of the area of the As $2 \mathrm{p}$ peaks to that of the Ga 2p peaks corrected for sensitivity was 1.6 and 1.5 for OT-18C and ET-20C.

The $\mathrm{O}$ 1s XPS region after $3 \mathrm{~min}$ of air exposure shown in Figure 3 (c) confirms the previous XPS peak assignments and the ellipsometry results. The 
intensity of the $\mathrm{O}$ 1s peak was reduced with increasing $\mathrm{C}$ chain length, with detection limits as shown by the control experiments in Figure 1(a) in the Supplemental Information. The area of the $\mathrm{C}$ 1s peak was normalized with respect to the number of $\mathrm{C}$ atoms (n) to account for the different $\mathrm{C}$ content of each alkanethiol. Figure 4(c) shows the area ratio of the normalized $\mathrm{C}$ 1s peak to 
405 length (red circles). The relative coverage per $\mathrm{C}$ atom was the same for the short-chain thiols (PT-3C, HT-6C, ODT-12C, and DT-12C), and rose steeply by a factor of $2-4 \times$ for the long-chain thiols (OT-18C and ET-20C). Water contact angle measurements performed after 3 min of exposure are shown in Figure ${ }_{410}^{4}$ (c) (black triangles). The contact angle depended on the length of the $\mathrm{C}$ chain, increasing from $55^{\circ}$ for $3 \mathrm{C}$ atoms to $108^{\circ}$ for $20 \mathrm{C}$ atoms, and with steep rises between PT-3C and HT-6C, and again from ODT-8C to DT-12C. The contact angle remained unchanged between HT-6C and ODT-8C, suggesting that the beneficial effect of additional $\mathrm{CH}_{2}$ groups in ODT-8C is balanced by the extra thiol (R-S-H) group, which increases the hydrophilicity of the film.

The initial thickness calculated for both the oxide and thiol layers that were resolved in the XPS is shown in Table 4, The thickness of the substrate oxides was reduced from $4.0 \AA$ for PT-3C to $0.8 \AA$ for ODT-8C. Accordingly, the calculated thiol thickness increased from $4.6 \AA$ for PT-3C to $31.3 \AA$ for ET-20C. thickness for all the thiols, except for HT-6C and ET-20C. For HT-6C the XPS thickness was smaller by $4.7 \AA$ than the ellipsometry thickness, while for ET-20C it was larger by $5.8 \AA$. The surface coverage calculated from XPS data (Figure 1(b) and Table 4) increased from 3.0 for PT-3C to a maximum of 5.0 thiol 425 molecules per $\mathrm{nm}^{2}$ for ET-20C. ODT-8C showed a higher coverage than PT-3C, HT-6C, and DT-12C, even though the latter has four more $\mathrm{CH}_{2}$ groups than the ODT-8C molecule. A linear fit of the surface coverage of the monothiols after 3 min of air exposure and as a function of the $\mathrm{C}$ chain length yielded a slope of $0.13 \pm 0.03$ thiols $/\left(\mathrm{nm}^{2} \mathrm{CH}_{2}\right)$ and an intercept of $2.2 \pm 0.4$ thiols $/ \mathrm{nm}^{2}$ (Figure $\left.{ }_{430} 1(\mathrm{~b})\right)$. A maximum coverage of 6.3 thiols per $\mathrm{nm}^{2}$ was calculated assuming that all surface As and Ga atoms bond with one thiol and using a GaAs lattice constant of $5.65 \AA$ [87]. On this basis, the ET-20C coverage was 0.8 monolayer (ML), which is a about 1.2 times higher than that of OT-18C. The procedure used for these calculations is provided in the Supporting Information. 


\subsection{Air Exposure for $30 \mathrm{~min}$}

Figure 3(b) shows the Ga 2p and As 2p XPS regions of samples after $30 \mathrm{~min}$ of ambient exposure. The oxidation of the substrate is shown by the re-growth of the $\mathrm{As}^{+3}$ oxide state $(\Delta \mathrm{BE}=+3.2 \mathrm{eV})$. The intensity of this peak decreased with the length of the $\mathrm{C}$ chain, and only in the case of ET-20C remained below

detection limits. The identification of a peak due to As-S bonds from PT-3C to OT-18C is hindered by an enhanced oxide re-growth, however, the peak $(\Delta \mathrm{BE}$ $=+1.3 \mathrm{eV}$ ) is still evident in the ET-20C spectrum, showing that the thiolate is still adsorbed on the surface. The Ga $2 \mathrm{p}$ state displayed the same trend as the As 2 p state. The peak assigned to Ga oxides and sulfide states shifted to lower binding energy with increasing $\mathrm{C}$ chain length due to the decreased contribution of the $\mathrm{Ga}^{+3}(\Delta \mathrm{BE}=+1.1 \mathrm{eV})$ oxide state upon substrate oxidation. The regrowth of this peak was inhibited with increasing chain length, and was still not detected for the ET-20C monolayer. The bulk Ga and As 2p peak shifted to lower binding energy with increasing $\mathrm{C}$ content of the thiol due to charge donation to the surface substrate atoms. Accordingly, the intensity of the $\mathrm{O}$ 1s peak (Figure 3(d)), which contains contributions from both Ga-O and As-O bonds, was reduced for longer $\mathrm{C}$ chains, but only the ET-20C layer kept oxygen atoms below detection limits. The corresponding ratio of the $\mathrm{As}^{+3}$ peak to the combined area of the As 2p peaks (Figure 4(a)) shows that the oxide peak increased more than 10 times in all cases, except for ET-20C. Similarly, the total oxygen content shown by the $\mathrm{O}$ 1s to As $2 \mathrm{p}$ ratio (Figure 4(b)) increased by a factor of 2 or more for chains with $18 \mathrm{C}$ atoms or less.

In Figure 3(f), the high binding energy shoulder at $163 \mathrm{eV}$ for chains with 8 , 12,18 and $20 \mathrm{C}$ atoms, qualitatively shows that $\mathrm{S}$ atoms from the alkanethiolate layers are still present on the surface after 30 min of air exposure, and that oxidation had little effect on their stability. If the $\mathrm{S}$ oxidized we would expect a peak for S-O bonding near $168 \mathrm{eV}$ [88]. Nevertheless, the stability of the short chains, PT-3C and HT-6C, can not be assessed based on these spectra because of the proximity of the Ga 3 s peak. In contrast, the ratio of the normalized $\mathrm{C}$

1s peak area to the combined area of As $2 p$ peaks shown in Figure 4(c) (blue 
diamonds), quantitatively shows the stability of the thiol layers. The ratio is about the same for each $\mathrm{C}$ chain at 3 and $30 \mathrm{~min}$ of air exposure based on the scatter in the data. This ratio, however, depends on the $\mathrm{C} 1 \mathrm{~s}$ peak and As $2 \mathrm{p}$ peak areas. Therefore, it is affected by the reduction of the $\mathrm{C}$ content when thiol desorbs, which reduces the attenuation and increases the area of the As $2 \mathrm{p}$ peaks. The thiol-dependent growth rate of the $\mathrm{As}^{+3}$ oxide peak and the changes in the attenuation of each thiol layer also hinder the quantification of chain desorption if it occurs.

\subsection{Reaction-Diffusion Model}

The one-dimensional diffusion of oxygen (or water vapor) across a continuous alkanethiolate layer and reaction at the surface was modeled using a differential mass balance with reaction only at the interface between the layer and GaAs. The alkanethiolate layer was assumed to be a thin uniform slab across which gas can diffuse in the direction perpendicular to the surface. The initial condition is the concentration of oxygen is zero throughout the alkanethiolate layer, $C(0, z)=0$, where $C(t, z)$ is the oxygen concentration in the layer $\left(\mathrm{mol} / \mathrm{cm}^{3}\right)$, which is a function of both time $t(\mathrm{~s})$ and distance $z(\mathrm{~cm})$. One boundary condition at the thiol-air interface is the concentration of oxygen equals that in air, $C(t, 0)=C_{\mathrm{O}_{2}}^{\text {air }}$. The second boundary condition at the thiol-substrate interface equates the oxygen flux through the thiol layer to the initial rate of oxidation of the GaAs surface, $-D \partial C / \partial z=k C(t, L) \sigma / A$, where $D$ is the oxygen diffusivity through the alkanethiolate layer $\left(\mathrm{cm}^{2} / \mathrm{s}\right), L$ is the thickness of the layer, $k$ is the rate coefficient for reaction of oxygen with GaAs terminated by the alkanethiolate $\left(\mathrm{cm}^{3} / \mathrm{mol} \mathrm{s}\right), \sigma$ is the $\operatorname{GaAs}(100)$ surface site density ( and $A$ is Avogadro's number. The reaction rate is assumed proportional to the surface site density because it is not known whether oxygen reacts initially with the atoms that terminate the surface or with As-Ga backbonds. Solving the differential mass balance with these conditions leads to

$$
C(t, z)=C_{O_{2}}^{a i r}\left[1-\left(\frac{\Phi^{2}}{1+\Phi^{2}}\right)\left(\frac{z}{L}\right)+\sum_{i=1}^{\infty} A_{i} e^{-\frac{\lambda_{i}^{2} D t}{L^{2}}} \sin \left(\lambda_{i} \frac{z}{L}\right)\right]
$$


where $\Phi$ is the Thiele modulus defined by $\sqrt{(k \sigma L) /(D A)}, \lambda_{i}$ are the eigenvalues that satisfy $\cot \lambda_{i}=-\Phi^{2} / \lambda_{i}$, and the $A_{i}$ coefficients depend on the eigenvalues.

Assuming the reaction between oxygen molecules and the surface is first order, the oxygen concentration was inserted into the reaction rate expression $d \theta / d t=k C(1-\theta)$, where $\theta$ is the fraction of surface sites that have oxidized, ${ }_{80}$ and the equation integrated to find the oxide coverage as a function of time less than $1800 \mathrm{~s}$ (30 min) where the XPS data show that no oxide formed for ET-20C. Choosing an alkanethiolate layer thickness equal to that of ET-20C $\left(L=2.55 \times 10^{-7} \mathrm{~cm}\right)$ and a reaction rate coefficient equal to $30 \mathrm{~cm}^{3} / \mathrm{mol} \mathrm{s}$, the model predicts that there is no dependence of the surface oxide coverage on the diffusivity of gas molecules in the $\mathrm{C}$ layer in the range $10^{-10}$ to $10^{-3} \mathrm{~cm}^{2} / \mathrm{s}$ because the values lie on top of each other as shown in Figure 5(a). Diffusivity values outside of this range produced negative oxygen concentrations or did not fit the coverage data from ellipsometry. In the literature, oxygen diffusivities of $2.5 \times 10^{-5} \mathrm{~cm}^{2} / \mathrm{s}$ in $n$-hexadecane have been reported and on the order of $10^{-4}$ $\mathrm{cm}^{2} / \mathrm{s}$ in $n$-hexadecanethiolate SAMs on $\mathrm{Cu}$ and Au surfaces [89, 90. These values are consistent with values typically found in liquids 91. Choosing an oxygen diffusivity of $1 \times 10^{-5} \mathrm{~cm}^{2} / \mathrm{s}$ and keeping the surface oxidation rate coefficient at $30 \mathrm{~cm}^{3} / \mathrm{mol} \mathrm{s}$, the model predicts that oxide regrowth is independent of the length of the alkanethiolate layer thickness over the range $2.55 \times 10^{-3} \mathrm{~cm}$ to $2.55 \times 10^{-12} \mathrm{~cm}$ as shown in Figure 5 (b). Different markers and colors were chosen but the curves lie on top of each other. The model predicts that diffusion of gas molecules through the $\mathrm{C}$ layer is fast over a wide range of thickness.

\section{Discussion}

The surface preparation steps remove all of the As and Ga oxides and terminate the GaAs surface with chlorine atoms when the surface is not rinsed (Figures 1(b) and 2 in Supporting Information). Although oxide is always detected on freshly prepared GaAs surfaces because samples are exposed to air in transit to the vacuum chamber, the stability of the Cl-terminated GaAs surface 
Table 5: Bond dissociation energies $(\mathrm{kJ} / \mathrm{mol})$ at $298 \mathrm{~K} 94$

\begin{tabular}{cccccc} 
& $\mathrm{As}$ & $\mathrm{Ga}$ & $\mathrm{Cl}$ & $\mathrm{S}$ & $\mathrm{O}$ \\
\hline $\mathrm{As}$ & 385.8 & 202.5 & 448 & $379.5 \pm 6.3$ & 484 \\
$\mathrm{Ga}$ & & $<106.4$ & 463 & $393 \pm 28$ & 374 \\
$\mathrm{Au}$ & & & & 418.4 & \\
\hline
\end{tabular}

in solution is indirectly supported by the XPS data on the thiol layers that show oxide growth increases with the time that a sample is exposed to air and decreases with the length of the alkyl chain on the thiol. The cleaning steps leave the surface predominately with As- $\mathrm{Cl}$ bonding since the As to Ga molar ratio is 1.8. Chlorine termination is a desirable starting point for thiol deposition and was the rationale for carrying over a thin liquid layer on the surface containing water and $\mathrm{HCl}$. Adding $\mathrm{HCl}$ via the carry over layer or intentionally to the thiol solution minimizes oxide that grows during the brief air exposure between cleaning and deposition.

Thiols could adsorb on the surface by directly displacing $\mathrm{Cl}$ via proton transfer from the $\mathrm{S}$ atom producing $\mathrm{HCl}$ or in a two step sequence where a protic solvent such as ethanol or water solvates the chlorine anion leaving a positivelycharged site on which thiolate $\left(\mathrm{RS}^{-}\right)$binds. The latter mechanism is supported by XPS data that shows $\mathrm{Cl}$ atoms were removed after rinsing with ethanol (Figure 1(b) in Supporting Information) or water. The formation of Ga-S bonds is more favorable based on bond energy (Table 5), but As-S bonds are formed on the predominantly As-rich surface after the acid clean. After the deposition of OT-18C and ET-20C, the surface remained As-rich since the As to Ga molar ratio was about 1.5. This is consistent with previous reports where a peak due to As-S bonds was identified in XPS spectra [57, 92]. The bond that S makes with As is about $10 \%$ weaker than that with $\mathrm{Au}$, which is closely associated with self-assembled monolayers of thiols 93.

The length of the alkane chain not only determined the thickness of a layer but also the density. The data in Figure 1(b) for the shortest possible air 
exposure show that the layer grows by $0.87 \pm 0.06 \AA$ for each methylene unit added to the chain. On gold a value as low as $0.56 \AA / \mathrm{CH}_{2}$ has been reported for short alkanethiols containing 2-6 C atoms that were poorly ordered, which increased markedly to $1.22 \pm 0.04 \AA / \mathrm{CH}_{2}$ based on the calculated lengths of the molecules and $1.5 \AA / \mathrm{CH}_{2}$ for chains containing 9-21 $\mathrm{C}$ atoms [84]. The intermediate value measured on GaAs indicates that alkanethiolates have a lower surface density and are less ordered than on gold. The magnitude of the length per methylene group on GaAs can also be attributed to the presence of substrate oxides for the shortest alkanethiols (about $4 \AA$ for PT-3C and $2 \AA$ for HT-6C, as determined by XPS).

The atomic density of a flat $\operatorname{GaAs}(100)$ surface is 6.3 atoms $/ \mathrm{nm}^{2}$, which is an area per atom of $16 \AA^{2}$. The surface density of 4.2 and 5.0 thiols $/ \mathrm{nm}^{2}$ calculated for OT-18C and ET-20C correspond to a coverage of 0.7 and $0.8 \mathrm{ML}$ or an area per thiol molecule of $24 \AA^{2}$ and $20 \AA^{2}$, respectively. The surface area of an alkanethiol with $22 \mathrm{C}$ atoms on $\mathrm{Au}(111)$ is $21.4 \AA^{2} /$ molecule 95] (12.0 atoms $/ \mathrm{nm}^{2}$ for $\mathrm{Au}(100)$ and 13.9 atoms $/ \mathrm{nm}^{2}$ for $\mathrm{Au}(111)$, based on the lattice parameters). An area of about $21.2 \AA^{2} /$ molecule was reported for a OT-18C monolayer deposited on $\mathrm{GaAs}(001)$ under a nitrogen blanket 58 .

The density of molecules in the thiol layers increases at a rate of $0.13 \pm 0.03$ molecules $/ \mathrm{nm}^{2}$ per $\mathrm{CH}_{2}$ for the monothiols based on the attenuation of the As 3d XPS peak (Figure 1(b)). Octanedithiol was excluded because ellipsometry and XPS results have shown that this layer is more stable and ordered compared to the corresponding monothiols [54, 55]. The alkane chains on the thiols must be floppy and interact not only with neighboring chains in the layer but also with the GaAs surface atoms covering adsorption sites. Smaller chains are floppier because there are fewer van der Waals interactions between $\mathrm{CH}_{2}$ groups in the chains to hold them in place, and the density of thiol molecules in the layer is lower as a result. The longer chains in the molecules OT-18C and ET-20C are packed more tightly together because of the stabilization energy provided by the additional $\mathrm{CH}_{2}$ groups.

Alkanethiolates adsorbed on GaAs at a coverage greater than $50 \%$ require 
a distortion of the surface to accommodate the molecules, since highly dense layers are incommensurate with the flat $\operatorname{GaAs}(100)$ surface [53, 58, 59]. The strength of the bond and the interaction between the long chains has been shown to distort the GaAs lattice, causing a surface reconstruction that allows the formation of crystalline-like SAMs on GaAs(100) [58]. AFM (Figure 3 in Supporting Information) shows that the GaAs starting surface is smooth (RMS roughness $0.2 \mathrm{~nm}$ ) and remains smooth after deposition of ET-20C (RMS 0.4 $\mathrm{nm}$ ) as shown in the Supporting Information. Phase domains of thiols with different orientations on the surface are possible and domain sizes of about 66$74 \AA$ have been reported for OT-18C [58].

Previous reports of OT-18C SAMs on Au and GaAs substrates showed a 570 peak at $2917 \mathrm{~cm}^{-1}$ for the $\mathrm{CH}_{2}$ asymmetric stretch, which is close to $2919 \mathrm{~cm}^{-1}$ for bulk crystalline OT-18C [84, 61, 58]. The values of $2919 \mathrm{~cm}^{-1}$ for OT-18C and $2918 \mathrm{~cm}^{-1}$ for ET-20C that we measured shows that only the layers with the longest chains were well-ordered with a high packing density and crystalline-like structure. In contrast, the peaks for DT-12C were shifted to higher wavenumber because the packing order of the molecules in the layer was reduced (coverage of 3.6 thiols $/ \mathrm{nm}^{2}$ or $28 \AA^{2} /$ molecule). The higher intensities of the OT-18C and ET-20C vibrational peaks is due to the higher C content and surface coverage compared to DT-12C (Figure 2). The initial thickness of the OT-18C and ET20C layers was less than the theoretical length of the molecules (Figure 1(a)), and the contribution of GaAs oxides was not significant (Figure 3(c)). Using the ellipsometry data, the tilt angle of the molecules with respect to the surface normal was about $28^{\circ}$ for $n=18$ and $19^{\circ}$ for $n=20$. A tilt angle of $14^{\circ}$ was reported for a OT-18C monolayer deposited on $\mathrm{GaAs}(001)$ under a nitrogen blanket, and an angle of $27^{\circ}$ for OT-18C on $\mathrm{Au}$ [58, 93.

585 The relative orientation between the adsorbed molecules and the angle of incidence of the IR electric field also affects light absorption and the intensities of the peaks. The dipole moment of the $\mathrm{CH}_{2}$ vibrational modes is perpendicular to the alkane chain. As the tilt angle decreases and the alkane chains are propped more upright or perpendicular to the surface, the dipole moment is 
better aligned with the electric field of the IR light [96]. The alignment increases the intensities of the vibrational modes in transmission FTIR done at normal incidence. Adding methylene groups not only adds $\mathrm{CH}_{2}$ groups and increases the coverage but also reduces the tilt angle, all of which increase the intensity of the C-H stretches in OT-18C and ET-20C which explains the $7-20 \times$ increase relative to DT-12C.

The threshold for ordering of the molecules in the layer is about $12 \mathrm{CH}_{2}$ groups. This is the length where we first detect the asymmetric and symmetric stretching vibrations, the oxygen coverage is significantly reduced (Figure 4(b)), and a pronounced increase in contact angle occurs (Figure $4(\mathrm{c})$ ). The effect on the FTIR peaks is nonlinear as attested to by the large increases in the intensities between DT-12C and OT-18C (difference of six C atoms) and again between OT-18C and ET-20C (difference of only two C atoms) as shown in Figure 2 The peak intensity is not only the result of adding $\mathrm{C}$ atoms to the chains but also the interaction between neighboring methylene groups that induces order in the layer. Lower tilting angles opens up surface area for more molecules to adsorb as shown by the smaller area per molecule, which increases the $\mathrm{S}$ bonded to the As atoms on the surface. The high binding energy shoulder in the $\mathrm{S} 2 \mathrm{p}$ region (Figure 3(e)) shows that more sulfur atoms are bound to the surface for the longer chains corroborating the surface coverage and surface density data. The theoretical dispersion energy of interaction per $\mathrm{CH}_{2}$ in hydrocarbon chains is about $6.9 \mathrm{~kJ} / \mathrm{mol}$ [97]. Therefore, the interaction energy in ET-20C is about $138 \mathrm{~kJ} / \mathrm{mol}$ for the hydrocarbon chain and 379.5 for the As-S bond. The total stabilization energy of one ET-20C molecule in the layer is about $517.5 \mathrm{~kJ} / \mathrm{mol}$. This energy is higher than the strong As-O bond and bonds with other adatoms 15 (Table 5). Based on bond energies, a threshold for molecular organization can be calculated by subtracting the energy of the As-S bond from that of As-O, and dividing the difference by the energy per $\mathrm{CH}_{2}$ group. The estimated threshold is about $15 \mathrm{C}$ atoms, which agrees reasonably with the threshold of $12 \mathrm{C}$ atoms found based on FTIR, XPS, and contact angle measurements in this study, and 20 the decrease in order reported in other studies [58, 98]. 
The change in the degree of wetting of the surface is a consequence of alkanethiolate deposition. The extent of this change scaled with the number of $\mathrm{C}$ atoms, with ET-20C yielding the highest water contact angle. Contact angles higher than $100^{\circ}$ were readily obtained when using thiols with 12 or more $\mathrm{CH}_{2}$ groups (Figure 4(c)). Hydrophobic films might be presumed to slow down oxygen and water diffusion, but this raises a central question. Is the protection the alkanethiolate chain affords the surface primarily the result of the resistance to gas diffusion of a hydrophobic carbon film or the resistance to reoxidation of the surface atoms because of the bonds made to $\mathrm{S}$ ?

Remarkably both XPS and ellipsometry showed that after 30 min of ambient exposure only ET-20C prevented oxidation of the substrate. The rate of oxide re-growth during the first $30 \mathrm{~min}$ of ambient exposure $(0.026 \AA / \mathrm{min})$ and the increase in overlayer thickness over 4 hours of exposure $(2.4 \AA)$ were the lowest for the ET-20C layer. The surface coverages presented in Table 4 showed that the ET-20C coverage is about $20 \%$ higher than that of OT-18C due to tighter packing of the longer molecules. Tighter packing of the alkanethiolate molecules could contribute more to retard the diffusion of oxygen and water vapor from the gas phase to the surface than the increase in the thickness of the layer would suggest. Tighter packing also increases the availability of $\mathrm{S}$ atoms at the interface with substrate As atoms.

The length of the $\mathrm{C}$ chain necessary to block oxygen from diffusing through the layer and oxidizing the GaAs substrate not only depends on the thickness of the molecule but also on the molecular density. Excluding the dithiol which yielded a lower oxide peak than expected from the trend, the O 1s XPS peak scaled by the As 2 p peak at 3 min decreased linearly with the length of the $\mathrm{C}$ chain for the monothiols as shown by the dashed line in Figure 4(b). The dithiol has a lower oxide ratio and the same contact angle as the shorter $6 \mathrm{C}$ atom chain monothiol (Figure 4(c)), which is consistent with $\mathrm{S}$ atoms exposed to air that have an affinity for oxygen and water vapor. The slope of the linear trendline for the monothiols is $-2 \times 10^{-2} / \mathrm{CH}_{2}$. The data point for the $20 \mathrm{C}$ atom thiol was not included because no oxide was present for the $18 \mathrm{C}$ atom 
chain. The amount of oxide produced in a given exposure time is the nominal rate, and the data in Figure 4(b) are proportional to the rate of reoxidation of the GaAs substrate.

There is more scatter in the data for the scaled $\mathrm{O}$ 1s peak at 30 min (Figure 4(b)). More GaAs oxide has grown because of the longer air exposure, and the slope of the best fit line increased to $-3.5 \times 10^{-2} / \mathrm{CH}_{2}$. The $\mathrm{As}^{+3}$ peak scaled by the As 2 p bulk peak area after 30 min of air exposure in Figure 4 (a) shows that the surfaces containing the 3 and $6 \mathrm{C}$ atom monothiols oxidize at about the same rate, and this rate is about four times higher than the surfaces covered by the 12 and $18 \mathrm{C}$ atom molecules, which also oxidize at about the same overall rate. No oxide is present yet for the $20 \mathrm{C}$ atom molecule, which blocks oxide formation for about 30 min based on XPS data in Figure 3(d). At long times the ellipsometry data plateau at different thickness for each thiol, since the onset for the diffusion limitation occurs earlier for short thiols. The mechanism for surface reoxidation for long times is different than at short times. At long times an oxide layer forms providing more resistance than the alkanethiolate layer. But at short times there is the question of whether the alkanethiolate molecules offer diffusion resistance or a kinetic barrier.

In order to find the oxygen diffusivity and rate coefficient for reaction of oxygen with the surface, the reaction-diffusion model was compared to the data for $n=18\left(L_{O T}=2.16 \times 10^{-7} \mathrm{~cm}\right)$ and $n=20\left(L_{E T}=2.55 \times 10^{-7} \mathrm{~cm}\right)$ since the XPS shows no oxide formed at short times. Two data sets were used: the net change in the thickness measured by ellipsometry referenced to the starting alkanethiolate thickness converted to an oxide coverage and the coverage calculated from the XPS data at 3 and 30 min. A monolayer thickness of $4.4 \AA$ ( $1 \mathrm{ML})$ based on $\mathrm{As}_{2} \mathrm{O}_{3}$ was assumed. Only the data for exposure times less than 30 min were fit because with ellipsometry the thiol layer could not be distinguished from the underlying oxide layer which grows with time, and the XPS data showed that no oxide formed for ET-20C. The results are shown in Figure 6. The ellipsometry data are shown as solid circles with error bars; the XPS as solid triangles without error bars. The model curves are shown 
as solid black lines. Since oxide regrowth is independent of diffusivity, a value of $10^{-5} \mathrm{~cm}^{2} / \mathrm{s}$ was chosen. Despite the dense and well-ordered structure of the OT-18C and ET-20C films on the GaAs surface, these layers are thin $(\leq 30 \AA)$ and oxygen diffusion is as fast as in liquids. The thickness increase of only 3.9 $\AA$ (based on the initial ellipsometry measurement) from $n=18$ to $n=20$ does not appreciably increase the barrier for the diffusion of oxygen.

The model shows that oxygen diffuses rapidly through the 2.1-2.6 $\mathrm{nm}$ thick C film and the oxygen concentration reaches reaches steady-state at the GaAs surface within one second of air exposure. The difference in the oxide that regrows with time for the two molecules chosen for comparison in Figure 6 is due to the reaction kinetics. Based on the ellipsometry data, the rate coefficient $k$ for reoxidation of the surface is $20-30 \mathrm{~cm}^{3} / \mathrm{mol} \mathrm{s}$ for the $18 \mathrm{C}$ atom chain and $10 \mathrm{~cm}^{3} / \mathrm{mol} \mathrm{s}$ for the $20 \mathrm{C}$ atom chain. Based on the XPS data, the rate coefficient is $60 \mathrm{~cm}^{3} / \mathrm{mol} \mathrm{s}$ for the $18 \mathrm{C}$ atom chain and less than $1 \mathrm{~cm}^{3} / \mathrm{mol}$ $\mathrm{s}$ for the $20 \mathrm{C}$ atom chain. The difference in reactivity is consistent with the higher density of S atoms in the ET-20C layer at the interface with As. The denser film reduces the reaction rate coefficient because there are more S-As bonds or the S-As bond is stronger because of better overlap. Without oxides the $\mathrm{As}^{+1}$ XPS state is a measure of the number of S-As bonds. The peak area ratio of $\mathrm{As}^{+1}$ to As metal is 0.07 for $18 \mathrm{C}$ atoms and 0.13 for $20 \mathrm{C}$ atoms after the shortest air exposure. For exposure times greater than $1500 \mathrm{~s}$, the coverage predicted by the model is greater than that measured with ellipsometry, which is consistent with the surface oxide providing a greater resistance to growth than the alkanethiolate film.

The diffusion through the thiol layers is fast and the oxygen concentration at the alkanethiolate-GaAs interface reaches steady-state quickly. The chain-tochain interactions and the bonding of $\mathrm{S}$ with the As atoms that terminate the surface direct the assembly of the film which determines the packing density of both chains and $\mathrm{S}$ atoms. The $\mathrm{S}$ atoms passivate the surface by bonding to the terminal As (Ga) atoms making them less prone to react with oxygen. Reoxidation is kinetically limited by the S-As ( $\mathrm{Ga}$ ) bonds, and the rate is controlled 
by the reaction of oxygen with the S-terminated surface, not diffusion of oxygen through the carbon layer.

\section{Conclusions}

Alkanethiolates chemically passivated clean $\operatorname{GaAs}(100)$ and protected it from ambient oxidation. The longest alkanethiol molecule, 1-eicosanethiol (ET-20C, $n=20$ ), had the highest packing density, the most order, and protected the surface from reoxidation in air for at least $30 \mathrm{~min}$. The molecules with the longer $\mathrm{C}$ chains have additional cohesion energy, which is essential for the formation of well-ordered and dense layers. The cohesion energy of the alkanethiols has to be large enough to direct the assembly of the layer and make the chains stand as upright as possible on the surface. The coverage of ET-20C was 0.8 monolayer, which formed a semisolid film on the surface. Although the film was well-ordered and tightly packed, the film thickness is only on the order of $2 \mathrm{~nm}$ and a reaction-diffusion model showed that oxygen can diffuse across it in less than one second. $\mathrm{S}$ offers protection to reoxidation by satisfying the dangling bonds on $\mathrm{Ga}$ and the predominant As atoms at the surface of the GaAs. The S-As bonds must be stable because they induce a surface reconstruction to accommodate a dense monolayer and they remain at the interface even after 30 min of ambient exposure. The bond strength between $\mathrm{S}$ and As not only protects the surface from reoxidation but determines how good a passivation layer can be formed. The S-As bonds anchor the molecules to GaAs and the cohesion energy between chains lifts them off of the surface. The result is a dense well-ordered layer that formed in solution in only 20 min at ambient conditions. The relatively short deposition time could broaden the integration of GaAs into devices.

\section{Acknowledgments}

The authors are grateful to Intel Corporation for funding and to Sanaz Gardner, Scott B. Clendenning, and Mansour Moinpour for valuable discussions. The 
authors thank Yissel Contreras for acquiring and analyzing the AFM images.

\section{References}

[1] J. A. del Alamo, Nanometre-Scale Electronics with III-V Compound Semiconductors, Nature 479 (2011) 317-323.

[2] R. Chau, B. Doyle, S. Datta, J. Kavalieros, K. Zhang, Integrated Nanoelectronics for the Future, Nat. Mater. 6 (2007) 810-812.

[3] M. Scarrozza, G. Pourtois, M. Houssa, M. Caymax, A. Stesmans, M. Meuris, M. M. Heyns, A Theoretical Study of the Initial Oxidation of the GaAs(001)- $\beta 2(2 x 4)$ Surface, Appl. Phys. Lett. 95 (2009) 2535041-3.

[4] C. C. Chang, P. H. Citrin, B. Schwartz, Chemical Preparation of GaAs Surfaces and Their Characterization by Auger Electron and X-ray Photoemission Spectroscopies, J. Vac. Sci. Technol. B 14 (1977) 943-952.

[5] R. P. Vasquez, B. F. Lewis, F. J. Grunthaner, Cleaning Chemistry of GaAs(100) and InSb(100) Substrates for Molecular Beam Epitaxy, J. Vac. Sci. Technol. B 1 (1983) 791-794.

[6] O. E. Tereshchenko, S. I. Chikichev, A. S. Terekhov, Composition and Structure of HCl-Isopropanol Treated and Vacuum Annealed GaAs(100) Surfaces, J. Vac. Sci. Technol. A 17 (1999) 2655-2662.

[7] Z. Liu, Y. Sun, F. Machuca, P. Pianetta, W. E. Spicer, R. F. W. Pease, Preparation of Clean GaAs(100) Studied by Synchrotron Radiation Photoemission, J. Vac. Sci. Technol. A 21 (2003) 212-218.

[8] M. V. Lebedev, D. Ensling, R. Hunger, T. Mayer, W. Jaegermann, Synchrotron Photoemission Spectroscopy Study of Ammonium Hydroxide Etching to Prepare Well-Ordered GaAs(100) Surfaces, Appl. Surf. Sci. 229 (2004) 226-232. 
[9] F. Lie, W. Rachmady, A. Muscat, A Comparison of Liquid and Gas Phase Surface Preparation of III-V Compound Semiconductors for Atomic Layer Deposition, Microelectron. Eng. 86 (2009) 122-127.

[10] C. J. Sandroff, R. N. Nottenburg, J. Bischoff, R. Bhat, Dramatic Enhancement in the Gain of a GaAs/AlGaAs Heterostructure Bipolar Transistor by Surface Chemical Passivation, Appl. Phys. Lett. 51 (1987) 33-35.

[11] E. Yablonovitch, C. J. Sandroff, R. Bhat, T. Gmitter, Nearly Ideal Electronic Properties of Sulfide Coated GaAs Surfaces, Appl. Phys. Lett. 51 (1987) 439-441.

[12] L. A. Farrow, C. J. Sandroff, M. C. Tamargo, Raman Scattering Measurements of Decreased Barrier Heights in GaAs Following Surface Chemical Passivation, Appl. Phys. Lett. 51 (1987) 1931-1933.

[13] C. J. Spindt, R. S. Besser, R. Cao, K. Miyano, C. R. Helms, W. E. Spicer, Photoemission Study of the Band Bending and Chemistry of Sodium Sulfide on GaAs(100), Appl. Phys. Lett. 54 (1989) 1148-1150.

[14] C. J. Sandroff, M. S. Hegde, L. A. Farrow, C. C. Chang, J. P. Harbison, Electronic Passivation of GaAs Surfaces Through the Formation of ArsenicSulfur Bonds, Appl. Phys. Lett. 54 (1989) 362-364.

[15] Z. H. Lu, M. J. Graham, X. H. Feng, B. X. Yang, Structure of S on Passivated GaAs(100), Appl. Phys. Lett. 62 (1993) 2932-2934.

[16] V. N. Bessolov, M. V. Lebedev, D. R. T. Zahn, Raman Scattering Study of Surface Barriers in GaAs Passivated in Alcoholic Sulfide Solutions, J. Appl. Phys. 82 (1997) 2640-2642.

[17] R. Driad, Z. H. Lu, S. Charbonneau, W. R. McKinnon, S. Laframboise, P. J. Poole, S. P. McAlister, Passivation of InGaAs Surfaces and InGaAs/InP Heterojunction Bipolar Transistors by Sulfur Treatment, Appl. Phys. Lett. 73 (1998) 665-667. 
[18] M. V. Lebedev, T. Mayer, W. Jaegermann, Sulfur Adsorption at GaAs(100) from Solution: Role of the Solvent in Surface Chemistry, Surf. Sci. 547 (2003) 171-183.

[19] B. Brennan, M. Milojevic, C. Hinkle, F. Aguirre-Tostado, G. Hughes, R. Wallace, Optimisation of the Ammonium Sulphide $\left(\mathrm{NH}_{4}\right)_{2} \mathrm{~S}$ Passivation Process on $\operatorname{In}_{0.53} \mathrm{Ga}_{0.47}$ As, Appl. Surf. Sci. 257 (2011) 4082-4090.

[20] H. Sugahara, M. Oshima, H. Oigawa, H. Shigekawa, Y. N. and, Synchrotron Radiation Photoemission Analysis for $\left(\mathrm{NH}_{4}\right)_{2} \mathrm{~S}_{x}$-Treated GaAs, J. Appl. Phys. 69 (1991) 4349-4353.

[21] H. Oigawa, J. Fan, Y. Nannichi, H. Sugahara, M. Oshima, Universal Passivation Effect of $\left(\mathrm{NH}_{4}\right)_{2} \mathrm{~S}_{x}$ Treatment on the Surface of III-V Compound Semiconductors, Jpn. J. Appl. Phys. 30 (1991) L322-L325.

[22] H. Sik, Y. Feurprier, C. Cardinaud, G. Turban, A. Scavennec, Reduction of Recombination Velocity on GaAs Surface by Ga-S and As-S Bond-Related Surface States from $\left(\mathrm{NH}_{4}\right)_{2} \mathrm{~S}_{x}$ Treatment, J. Electrochem. Soc. 144 (1997) 2106-2115.

[23] Y. Fukuda, Y. Suzuki, N. Sanada, M. Shimomura, S. Masuda, $\left(\mathrm{NH}_{4}\right)_{2} \mathrm{~S}_{x^{-}}$ Treated $\operatorname{InAs}(001)$ Surface Studied by X-ray Photoelectron Spectroscopy and Low-Energy Electron Diffraction, Phys. Rev. B 56 (1997) 1084-1086.

[24] M.-G. Kang, H.-H. Park, Effect of Prepared GaAs Surface on the Sulfidation with $\left(\mathrm{NH}_{4}\right)_{2} \mathrm{~S}_{x}$ Solution, J. Vac. Sci. Technol. A 17 (1999) 88-92.

[25] D. Petrovykh, M. Yang, L. Whitman, Chemical and Electronic Properties of Sulfur-Passivated InAs Surfaces, Surf. Sci. 523 (2003) 231-240.

[26] S. Arabasz, E. Bergignat, G. Hollinger, J. Szuber, XPS Analysis of Surface Chemistry of Near Surface Region of Epiready GaAs(100) Surface Treated with $\left(\mathrm{NH}_{4}\right)_{2} \mathrm{~S}_{x}$ Solution, Appl. Surf. Sci. 252 (2006) 7659-7663. 
[27] L. Koenders, M. Blmacher, W. Mnch, Electronic Properties of Sulfur Adsorbed on Cleaved GaAs Surfaces, J. Vac. Sci. Technol. B 6 (1988) 14161420.

[28] P. Moriarty, B.Murphy, L. Roberts, A. A. Cafolla, Photoelectron CoreLevel Spectroscopy and Scanning-Tunneling-Microscopy Study of the

[29] T. Tiedje, K. M. Colbow, D. Rogers, Z. Fu, W. Eberhardt, Ultraviolet Photoemission Studies of GaAs(100) Surfaces Chemically Stabilized by $\mathrm{H}_{2} \mathrm{~S}$ Treatments, J. Vac. Sci. Technol. B 7 (1989) 837-840.

[30] K. M. Geib, J. Shin, C. W. Wilmsen, Formation of S-GaAs Surface Bonds,

[31] J. Shin, K. M. Geib, C. W. Wilmsen, Z. Lilliental-Weber, The Chemistry of Sulfur Passivation of GaAs Surfaces, J. Vac. Sci. Technol. A 8 (1990) 1894-1898.

[32] G. Y. Gu, E. A. Ogryzlo, P. C. Wong, M. Y. Zhou, K. A. R. Mitchell,

[34] V. N. Bessolov, E. V. Konenkova, M. V. Lebedev, A Comparison of the Effectiveness of GaAs Surface Passivation with Sodium and Ammonium Sulfide Solutions, Phys. Solid State 39 (1997) 54-57.

[35] D. Liu, T. Zhang, R. A. LaRue, J. S. Harris, T. W. Sigmon, Deep Level Transient Spectroscopy Study of GaAs Surface States Treated with InorThe Passivation of Gallium Arsenide Surfaces with Atomic Sulfur, J. Appl. Phys. 72 (1992) 762-765.

[33] R. S. Besser, C. R. Helms, Comparison of Surface Properties of Sodium Sulfide and Ammonium Sulfide Passivation of GaAs, J. Appl. Phys. 65 (1989) 4306-4310. ganic Sulfides, Appl. Phys. Lett. 53 (1988) 1059-1061. 
[36] T. Tiedje, P. C. Wong, K. A. R. Mitchell, W. Eberhardt, Z. Fu, D. Sondericker, UV Photoemission Study of Sulfide Passivated GaAs Surfaces, Solid State Commun. 70 (1989) 355-358.

[37] R. N. Nottenburg, C. J. Sandroff, D. A. Humphrey, T. H. Hollenbeck, R. Bhat, Near-Ideal Transport in an AlGaAs/GaAs Heterostructure Bipolar Transistor by $\mathrm{Na}_{2} \mathrm{~S} \cdot 9 \mathrm{H}_{2} \mathrm{O}$ Regrowth, Appl. Phys. Lett. 52 (1988) 218220.

[38] M. S. Carpenter, M. R. Melloch, M. S. Lundstrom, S. P. Tobin, Effects of $\mathrm{Na}_{2} \mathrm{~S}$ and $\left(\mathrm{NH}_{4}\right)_{2} \mathrm{~S}$ Edge Passivation Treatments on the Dark Currentvoltage Characteristics of GaAs pn Diodes, Appl. Phys. Lett. 52 (1988) $2157-2159$.

[39] J.-W. Kim, M.-G. Kang, H.-H. Park, Investigation on the Surface Characteristics of GaAs after Sulfuric-Vapor Treatment, Thin Solid Films 355-356 (1999) 423-429.

[40] M. M. Frank, G. D. Wilk, D. Starodub, T. Gustafsson, E. Garfunkel, Y. J. Chabal, J. Grazul, D. A. Muller, $\mathrm{HfO}_{2}$ and $\mathrm{Al}_{2} \mathrm{O}_{3}$ Gate Dielectrics on GaAs Grown by Atomic Layer Deposition, Appl. Phys. Lett. 86 (2005) 1529041-3.

[41] M. L. Huang, Y. C. Chang, C. H. Chang, Y. J. Lee, P. Chang, Surface Passivation of III-V Compound Semiconductors Using Atomic-LayerDeposition-Grown $\mathrm{Al}_{2} \mathrm{O}_{3}$, Appl. Phys. Lett. 87 (2005) 2521041-3.

[42] Y. Xuan, H.-C. Lin, P. D. Ye, Simplified Surface Preparation for GaAs Passivation Using Atomic Layer-Deposited High-k Dielectrics, IEEE T. Electron Dev. 54 (2007) 1811-1817.

[43] F. S. Aguirre-Tostado, M. Milojevic, K. J. Choi, H. C. Kim, C. L. Hinkle, E. M. Vogel, J. Kim, T. Yang, Y. Xuan, P. D. Ye, R. M. Wallace, S Passivation of GaAs and Band Bending Reduction upon Atomic Layer Deposition of $\mathrm{HfO}_{2} / \mathrm{Al}_{2} \mathrm{O}_{3}$ Nanolaminates, Appl. Phys. Lett. 93 (2008) 0619071-3. 
[44] C. L. Hinkle, A. M. Sonnet, E. M. Vogel, S. McDonnell, G. J. Hughes, M. Milojevic, B. Lee, F. S. Aguirre-Tostado, K. J. Choi, H. C. Kim, J. Kim, R. M. Wallace, GaAs Interfacial Self-Cleaning by Atomic Layer Deposition, Appl. Phys. Lett. 92 (2008) 0719011-3.

[45] B. Granados-Alpizar, A. J. Muscat, Surface Reactions of $\mathrm{TiCl}_{4}$ and $\mathrm{Al}\left(\mathrm{CH}_{3}\right)_{3}$ on $\mathrm{GaAs}(100)$ During the First Half-Cycle of Atomic Layer Deposition, Surf. Sci. 605 (2011) 1243-1248.

[46] S. McDonnell, H. Dong, J. M. Hawkins, B. Brennan, M. Milojevic, F. S. Aguirre-Tostado, D. M. Zhernokletov, C. L. Hinkle, J. Kim, R. M. Wallace, Interfacial Oxide Re-Growth in Thin Film Metal Oxide III-V Semiconductor Systems, Appl. Phys. Lett. 100 (2012) 141606 1-4.

[47] D. Shahrjerdi, E. Tutuc, S. K. Banerjee, Impact of Surface Chemical Treatment on Capacitance-Voltage Characteristics of GaAs Metal-OxideSemiconductor Capacitors with $\mathrm{Al}_{2} \mathrm{O}_{3}$ Gate Dielectric, Appl. Phys. Lett. 91 (2007) 0635011-3.

[48] S. R. Lunt, P. G. Santangelo, N. S. Lewis, Passivation of GaAs Surface Recombination with Organic Thiols, J. Vac. Sci. Technol. B 9 (1991) 23332336.

[49] C. W. Sheen, J.-X. Shi, J. Mirtensson, A. N. Parikh, D. L. Allara, A New Class of Organized Self- Assembled Monolayers: Alkane Thiols on GaAs(100), J. Am. Chem. Soc. 114 (1992) 1514-1515.

[50] J. F. Dorsten, J. E. Maslar, P. W. Bohn, Near-Surface Electronic Structure in GaAs(100) Modified with Self-Assembled monolayers of Octadecylthiol, Appl. Phys. Lett. 66 (1995) 1755-1757.

[51] T. Baum, S. Ye, K. Uosaki, Formation of Self-Assembled Monolayers of Alkanethiols on GaAs Surface with in Situ Surface Activation by Ammonium Hydroxide, Langmuir 15 (1999) 8577-8579. 
[52] S. Ye, G. Li, H. Noda, K. Uosaki, M. Osawa, Characterization of SelfAssembled Monolayers of Alkanethiol on GaAs Surface by Contact Angle and Angle-Resolved XPS Measurements, Surf. Sci. 529 (2003) 163-170.

[53] C. L. McGuiness, A. Shaporenko, C. K. Mars, S. Uppili, M. Zharnikov, D. L. Allara, Molecular Self-Assembly at Bare Semiconductor Surfaces: Preparation and Characterization of Highly Organized Octadecanethiolate Monolayers on GaAs(001), J. Am. Chem. Soc. 128 (2006) 5231-5243.

[54] Y. Jun, X.-Y. Zhu, J. W. P. Hsu, Formation of Alkanethiol and Alkanedithiol Monolayers on GaAs(001), Langmuir 22 (2006) 3627-3632.

[55] T. Aqua, H. Cohen, A. Vilan, R. Naaman, Long-Range Substrate Effects on the Stability and Reactivity of Thiolated Self-Assembled Monolayers, J. Phys. Chem. C 111 (2007) 16313-16318.

[56] L. M. Rodriguez, J. E. Gayone, E. A. Sanchez, O. Grizzi, B. Blum, R. C. Salvarezza, L. Xi, W. M. Lau, Gas Phase Formation of Dense Alkanethiol Layers on GaAs(110), J. Am. Chem. Soc. 129 (2007) 7807-7813.

[57] C. L. McGuiness, A. Shaporenko, M. Zharnikov, A. V. Walker, D. L. Allara, Molecular Self-Assembly at Bare Semiconductor Surfaces: Investigation of the Chemical and Electronic Properties of the Alkanethiolate-GaAs(001) Interface, J. Phys. Chem. C 111 (2007) 4226-4234.

[58] C. L. McGuiness, D. Blasini, J. P. Masejewski, S. Uppili, O. M. Cabarcos, D. Smilgies, D. L. Allara, Molecular Self-Assembly at Bare Semiconductor Surfaces: Characterization of a Homologous Series of n-Alkanethiolate Monolayers on GaAs(001), ACS Nano 1 (2007) 30-49.

[59] O. Voznyy, J. J. Dubowski, Structure of Thiol Self-Assembled Monolayers Commensurate with the GaAs(001) Surface, Langmuir 24 (2008) 1329913305. 
[60] T. Huang, T. Lin, T. Teng, Y. Lai, W. Hung, Adsorption and Thermal Reaction of Short-Chain Alkanethiols on GaAs(100), Surf. Sci. 603 (2009) $1244-1252$.

[61] C. L. McGuiness, G. A. Diehl, D. Blasini, D.-M. Smilgies, M. Zhu, N. Samarth, T. Weidner, N. Ballav, M. Zharnikov, D. L. Allara, Molecular Self-Assembly at Bare Semiconductor Surfaces: Cooperative Substrate Molecule Effects in Octadecanethiolate Monolayer Assemblies on GaAs(111), (110), and (100), ACS Nano 4 (2010) 3447-3465.

[62] H. Ohno, M. Motomatsu, W. Mizutani, H. Tokumoto, AFM Observation of Self-Assembled Monolayer Films on GaAs(110), Jpn. J. Appl. Phys. 34 (1995) 1381-1386.

[63] K. Adlkofer, M. Tanaka, Stable Surface Coating of Gallium Arsenide with Octadecylthiol Monolayers, Langmuir 17 (2001) 4267-4273.

[64] N. K. Singh, D. C. Doran, Decomposition Reactions of Ethanethiol on GaAs(100), Surf. Sci. 422 (1999) 50-64.

[65] S. Donev, N. Brack, N. J. Paris, P. J. Pigram, N. K. Singh, B. F. Usher, Surface Reactions of 1-Propanethiol on GaAs(100), Langmuir 21 (2005) 1866-1874.

[66] G. Nesher, A. Vilan, H. Cohen, D. Cahen, F. Amy, C. Chan, J. Hwang, A. Kahn, Energy Level and Band Alignment for GaAs-Alkylthiol Monolayer-Hg Junctions from Electrical Transport and Photoemission Experiments, J. Phys. Chem. B 110 (2006) 14363-14371.

[67] X. Ding, K. Moumanis, J. J. Dubowski, L. Tay, N. L. Rowell, Fourier-Transform Infrared and Photoluminescence Spectroscopies of SelfAssembled Monolayers of Long-Chain Thiols on (001) GaAs, J. Appl. Phys. 99 (2006) 0547011-6. 
[68] D. M. Wieliczka, X. Ding, J. J. Dubowski, X-ray Photoelectron Spectroscopy Study of Self-Assembled Monolayers of Alkanethiols on (001) GaAs, J. Vac. Sci. Technol. A 24 (2006) 1756-1759.

[69] J. Dubowski, O. Voznyy, G. Marshall, Molecular Self-Assembly and Passivation of $\operatorname{GaAs}(001)$ with Alkanethiol Monolayers: A View Towards BioFunctionalization, Appl. Surf. Sci. 256 (2010) 5714-5721.

[70] Z. Li, S.-C. Chang, R. S. Williams, Self-Assembly of Alkanethiol Molecules onto Platinum and Platinum Oxide Surfaces, Langmuir 19 (2003) 67446749 .

[71] A. Carvalho, M. Geissler, H. Schmid, B. Michel, E. Delamarche, SelfAssembled Monolayers of Eicosanethiol on Palladium and Their Use in Microcontact Printing, Langmuir 18 (2002) 2406-2412.

[72] C. Zhou, A. V. Walker, UV Photooxidation of a Homologous Series of nAlkanethiolate Monolayers on GaAs(001): A Static SIMS Investigation, J. Phys. Chem. C 112 (2008) 797-805.

[73] H. Lu, M. Kind, A. Terfort, M. Zharnikov, Structure of Self-Assembled Monolayers of Partially Fluorinated Alkanethiols on GaAs(001) Substrates, J. Phys. Chem. C 117 (2013) 26166-26178.

[74] J. Massies, J. P. Contour, Substrate Chemical Etching Prior to MolecularBeam Epitaxy: An X-ray Photoelectron Spectroscopy Study of GaAs 001 Surfaces Etched by the $\mathrm{H}_{2} \mathrm{SO}_{4}-\mathrm{H}_{2} \mathrm{O}_{2}-\mathrm{H}_{2} \mathrm{O}$ Solution, J. Appl. Phys. 58 (1985) 806-810.

[75] T. Hou, C. M. Greenlief, S. W. Keller, L. Nelen, J. F. Kauffman, Passivation of GaAs(100) with an Adhesion Promoting Self-Assembled Monolayer, Chem. Mater. 9 (1997) 3181-3186.

[76] J. Moulder, W. Stickle, P. Sobol, K. Bomben, Handbook of X-ray Photoelectron Spectroscopy, Physical Electronics, Inc. Eden Prairie, MN, 1995. 
[77] D. A. Shirley, High-Resolution X-Ray Photoemission Spectrum of the Valence Bands of Gold, Physical Review B 5 (1972) 4709-4714.

[78] C. D. Wagner, L. E. Davis, M. V. Zeller, J. A. Taylor, R. H. Raymond, L. H. Gale, Empirical Atomic Sensitivity Factors for Quantitative Analysis by Electron Spectroscopy for Chemical Analysis, Surf. Interface Anal. 3 (1981) 211-225.

[79] J. H. Scofield, Hartree-Slater Subshell Photoionization Cross-sections at 1254 and 1487 eV, J. Electron Spectrosc. Relat. Phenom. 8 (1976) 129137.

[80] E. McCafferty, J. P. Wightman, Determination of the Concentration of Surface Hydroxyl Groups on Metal Oxide Films by a Quantitative XPS Method, Surf. Interface Anal. 26 (1998) 549-564.

[81] M. P. Seah, I. S. Gilmore, Simplified Equations for Correction Parameters for Elastic Scattering Effects in AES and XPS for Q, Beta and Attenuation Lengths, Surf. Interface Anal. 31 (2001) 835-846.

[82] M. P. Seah, S. J. Spencer, Ultrathin $\mathrm{SiO}_{2}$ on Si. II. Issues in Quantification of the Oxide Thickness, Surf. Interface Anal. 33 (2002) 640-652.

[83] M. P. Seah, S. J. Spencer, Ultrathin $\mathrm{SiO}_{2}$ on Si. I. Quantifying and Removing Carbonaceous Contamination, J. Vac. Sci. Technol. A 21 (2003) 345-352.

[84] M. D. Porter, T. B. Bright, D. L. Allara, C. E. D. Chidsey, Spontaneously Organized Molecular Assemblies. 4. Structural Characterization of n-Alkyl Thiol Monolayers on Gold by Optical Ellipsometry, Infrared Spectroscopy, and Electrochemistry, J. Am. Chem. Soc. 109 (1987) 3559-3568.

[85] B. Brennan, G. Hughes, Identification and Thermal Stability of the Native Oxides on InGaAs Using Synchrotron Radiation Based Photoemission, J. Appl. Phys. 108 (2010) 053516. 
[86] H. A. Budz, M. C. Biesinger, R. R. LaPierre, Passivation of GaAs by Octadecanethiol Self-Assembled Monolayers Deposited from Liquid and Vapor Phases, J. Vac. Sci. Technol. B 27 (2009) 637-648.

[87] J. S. Blakemore, Semiconducting and Other Major Properties of Gallium Arsenide, J. Appl. Phys. 53 (1982) R123-R181.

[88] H. H. Park, A. Ivanisevic, Formation and Characterization of Homogeneous and Mixed Self-Assembled Monolayers of Peptides and Alkanethiols on Indium Phosphide Surfaces, J. Phys. Chem. C 111 (2007) 3710-3718.

[89] L.-K. Ju, C. S. Ho, Oxygen Diffusion Coefficient and Solubility in nHexadecane, Biotechnol. Bioeng. 34 (1989) 1221-1224.

[90] P. Srivastava, W. G. Chapman, P. E. Laibinis, Molecular Dynamics Simulation of Oxygen Transport through n-Alkanethiolate Self-Assembled Monolayers on Gold and Copper, J. Phys. Chem. B 113 (2009) 456-464.

[91] R. B. Bird, W. E. Stewart, E. N. Lightfoot, Transport Phenomena, 2nd Edition, John Wiley \& Sons, 2002.

[92] A. Shaporenko, K. Adlkofer, L. S. O. Johansson, M. Tanaka, M. Zharnikov, Functionalization of GaAs Surfaces with Aromatic Self-Assembled Monolayers: A Synchrotron-Based Spectroscopic Study, Langmuir 19 (2003) 4992-4998.

[93] P. E. Laibinis, G. M. Whitesides, D. L. Allara, Y.-T. Tao, A. N. Parikh, R. G. Nuzzo, Comparison of the Structures and Wetting Properties of SelfAssembled Monolayers of n-Alkanethiols on the Coinage Metal Surfaces, $\mathrm{Cu}, \mathrm{Ag}, \mathrm{Au}, \mathrm{J} . \mathrm{Am}$. Chem. Soc. 113 (1991) 7152-7167.

[94] D. R. Lide (Ed.), CRC Handbook of Chemistry \& Physics, Online Edition, CRC Press/Taylor and Francis Group, Boca Raton, FL, 2013.

[95] L. Strong, G. M. Whitesides, Structures of Self-Assembled Monolayer Films of Organosulfur Compounds Adsorbed on Gold Single Crystals: Electron Diffraction Studies, Langmuir 4 (1988) 546-558. 
[96] V. P. Tolstoy, I. V. Chernyshova, V. A. Skryshevsky, Handbook of Infrared Spectroscopy of Ultrathin Films, John Wiley \& Sons, Inc., 2003.

[97] J. N. Israelachvili, Intermolecular \& Surface Forces, Elsevier, 2011.

[98] F. Schreiber, Structure and Growth of Self-Assembling Monolayers, Progress in Surface Science 65 (2000) 151-256. 


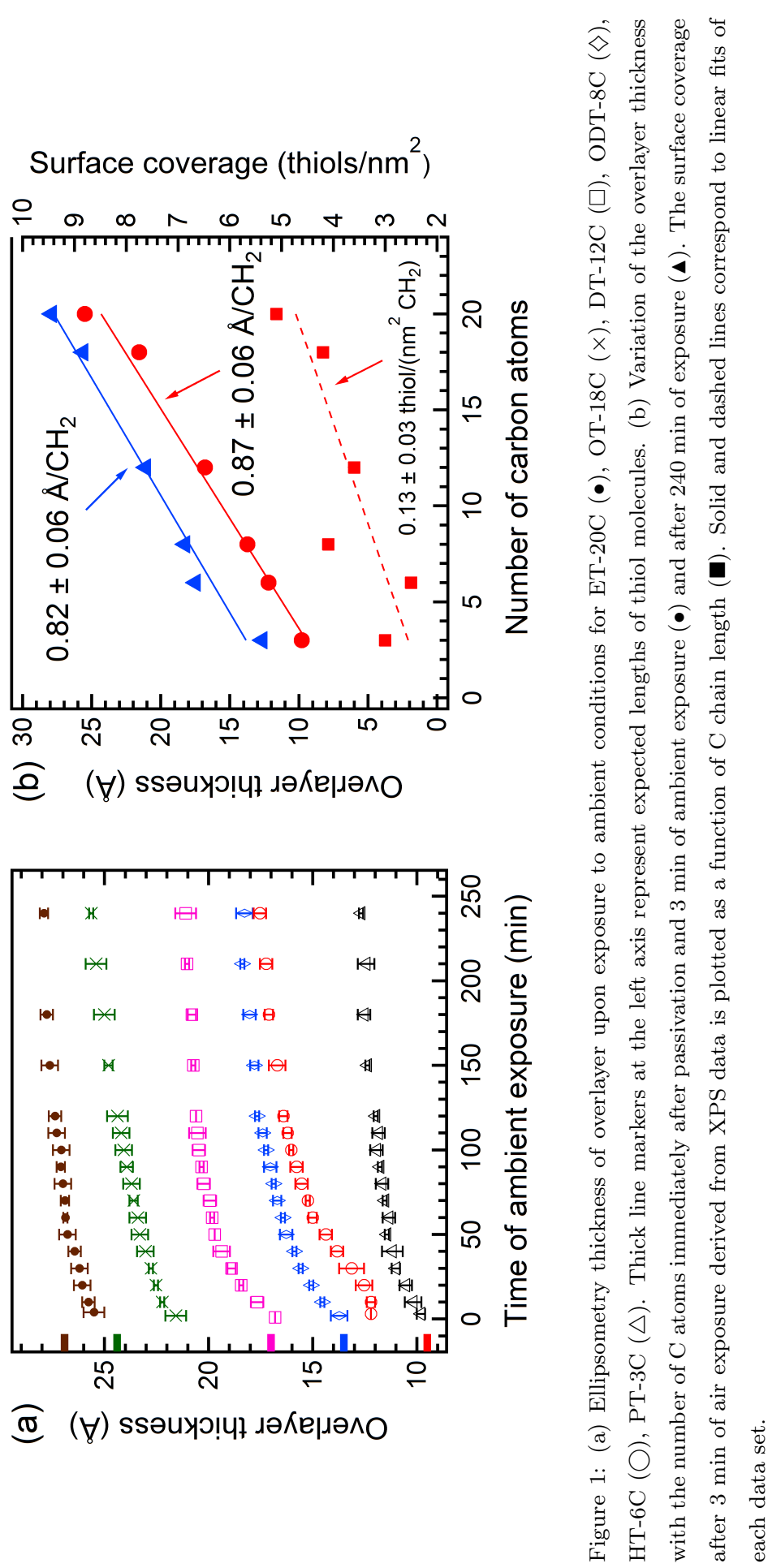




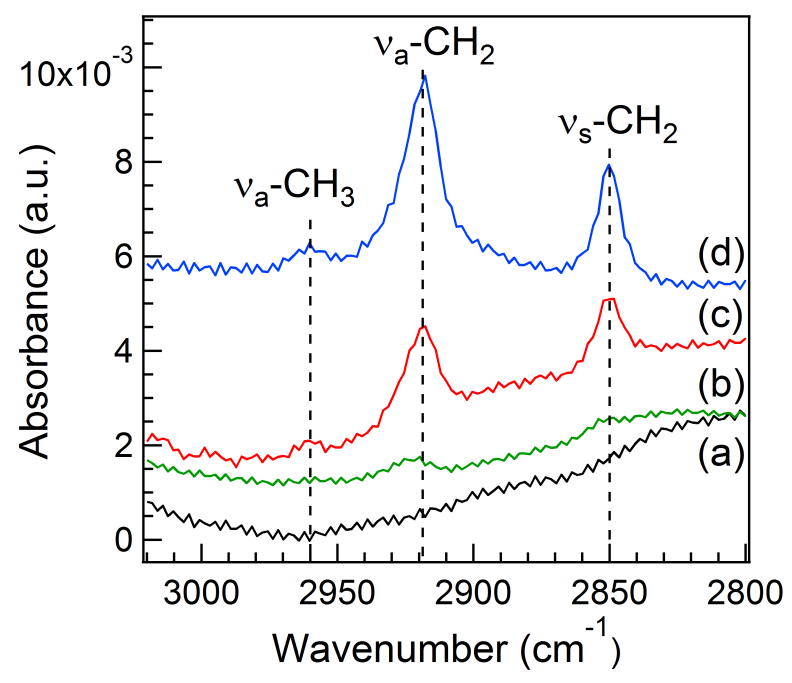

Figure 2: Transmission FTIR spectra of (a) native oxide GaAs, and GaAs treated with (b) DT-12C, (c) OT-18C, and (d) ET-20C. 

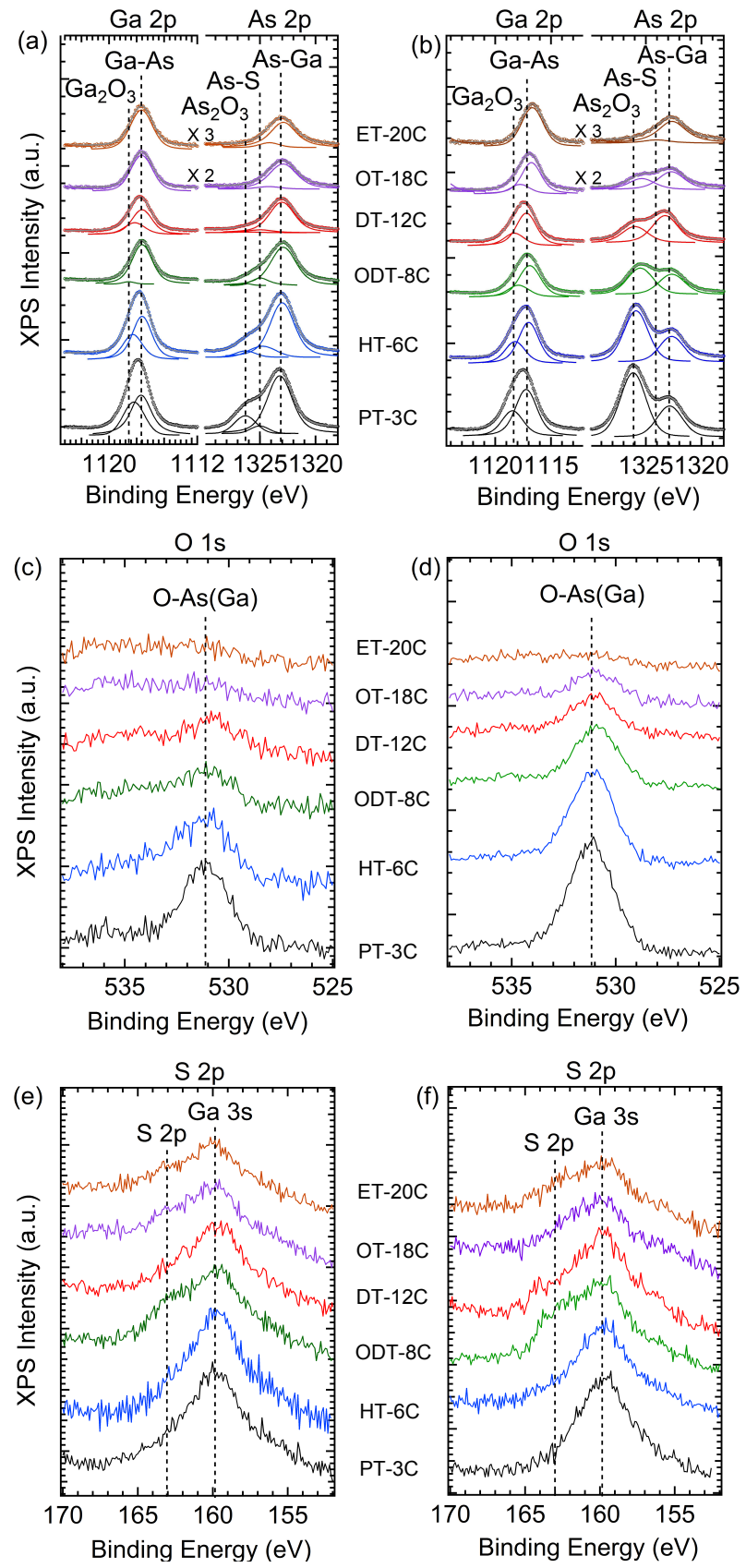

Figure 3: XPS spectra of As 2p and Ga 2p states after (a) 3 min and (b) 30 min of ambient exposure, O 1s after (c) 3 min and (d) 30 min of ambient exposure, and S 2p after (e) 3 min and (f) 30 min of ambient exposure. Vertical dashed lines are guides to the eye for the position of the respective peaks. Circle markers in (a) and (b) correspond to data and solid lines to fitting curves. Solid lines in (c)-(f) correspond to data. 

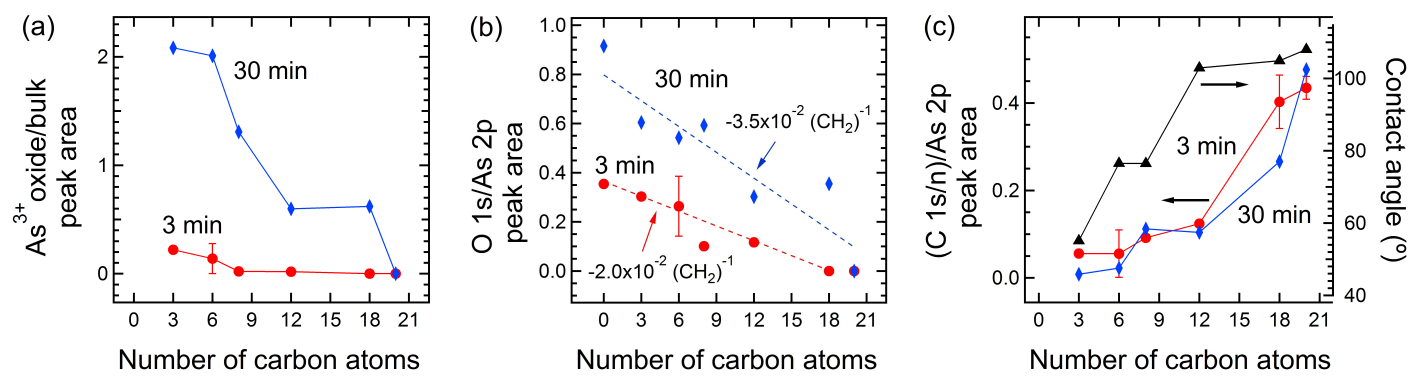

Figure 4: Ratio of (a) oxide to bulk As 2p peak areas, (b) O 1s peak area to all the As 2p peaks area, (c) C 1s peak area to all the As 2p peaks area for $3 \mathrm{~min}(\bullet)$ and $30 \mathrm{~min}$ of ambient exposure ( $)$, and (c) water contact angle ( $\mathbf{\Delta}$ ) for 3 min of ambient exposure as a function of number of $\mathrm{C}$ atoms (n). Solid lines are guides to the eye and dashed lines correspond to linear fits.
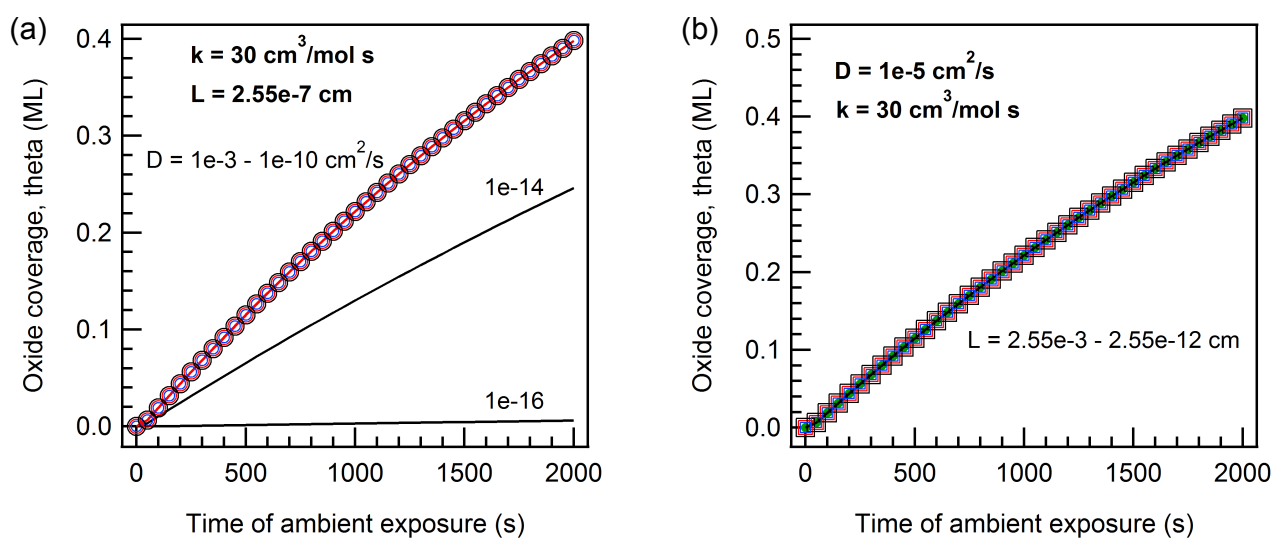

Figure 5: Calculated oxide coverage (solid black lines and markers) as a function of time for a) fixed $\mathrm{k}=30 \mathrm{~cm}^{3} / \mathrm{mol} \mathrm{s}$ and $\mathrm{L}=2.55 \times 10^{-7} \mathrm{~cm}$ with $\mathrm{D}$ varying from $1 \times 10^{-3}-1 \times 10^{-16}$ $\mathrm{cm}^{2} / \mathrm{s}$ and $\mathrm{b}$ ) fixed $\mathrm{D}=1 \times 10^{-5} \mathrm{~cm}^{2} / \mathrm{s}$ and $\mathrm{k}=30 \mathrm{~cm}^{3} / \mathrm{mol} \mathrm{s}$ with $\mathrm{L}$ varying over the range $2.55 \times 10^{-3}-2.55 \times 10^{-12} \mathrm{~cm}$. 


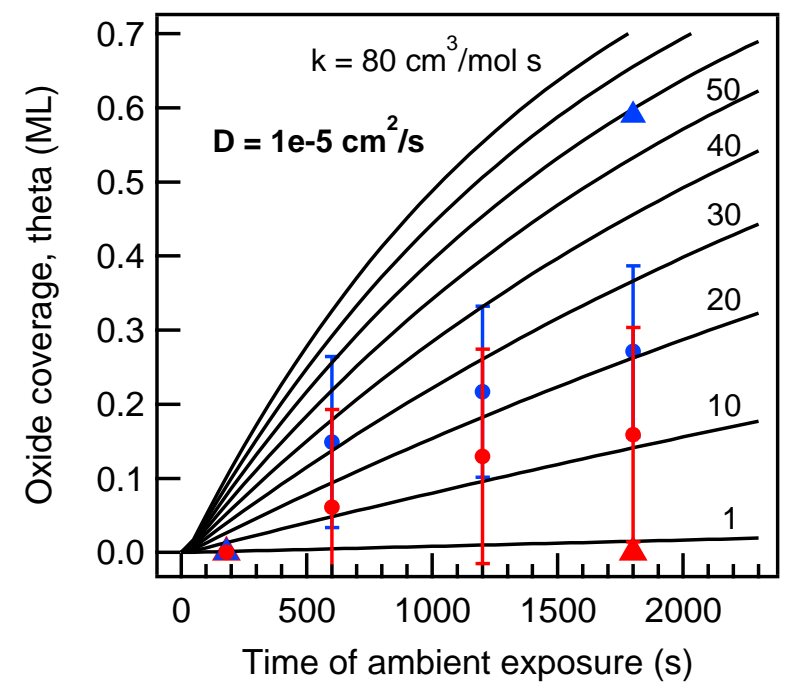

Figure 6: Calculated oxide coverage (solid black lines) from Equation 1 as a function of time for different values of the reaction rate coefficient $k\left(\mathrm{~cm}^{3} / \mathrm{mol} \mathrm{s}\right)$. The oxygen diffusivity $D$ was fixed at $1 \times 10^{-5} \mathrm{~cm}^{2} / \mathrm{s}$, and the alkanethiolate thickness $L$ was fixed at $2.5 \times 10^{-7}$ $\mathrm{cm}$. The oxide coverage was calculated from the net change in the overlayer thickness of thiol-treated GaAs measured by ellipsometry $(\bullet)$ and from XPS peak areas $(\boldsymbol{\Lambda})$. Blue data points correspond to OT-18C and red points to ET-20C. 